NASA/TM-2012-217115

\title{
Effect of Internal Clearance on Load Distribution and Life of Radially Loaded Ball and Roller Bearings
}

Fred B. Oswald and Erwin V. Zaretsky

Glenn Research Center, Cleveland, Ohio

Joseph V. Poplawski

J.V. Poplawski \& Associates 


\section{NASA STI Program . . . in Profile}

Since its founding, NASA has been dedicated to the advancement of aeronautics and space science. The NASA Scientific and Technical Information (STI) program plays a key part in helping NASA maintain this important role.

The NASA STI Program operates under the auspices of the Agency Chief Information Officer. It collects, organizes, provides for archiving, and disseminates NASA's STI. The NASA STI program provides access to the NASA Aeronautics and Space Database and its public interface, the NASA Technical Reports Server, thus providing one of the largest collections of aeronautical and space science STI in the world. Results are published in both non-NASA channels and by NASA in the NASA STI Report Series, which includes the following report types:

- TECHNICAL PUBLICATION. Reports of completed research or a major significant phase of research that present the results of NASA programs and include extensive data or theoretical analysis. Includes compilations of significant scientific and technical data and information deemed to be of continuing reference value. NASA counterpart of peer-reviewed formal professional papers but has less stringent limitations on manuscript length and extent of graphic presentations.

- TECHNICAL MEMORANDUM. Scientific and technical findings that are preliminary or of specialized interest, e.g., quick release reports, working papers, and bibliographies that contain minimal annotation. Does not contain extensive analysis.

- CONTRACTOR REPORT. Scientific and technical findings by NASA-sponsored contractors and grantees.
- CONFERENCE PUBLICATION. Collected papers from scientific and technical conferences, symposia, seminars, or other meetings sponsored or cosponsored by NASA.

- SPECIAL PUBLICATION. Scientific, technical, or historical information from NASA programs, projects, and missions, often concerned with subjects having substantial public interest.

- TECHNICAL TRANSLATION. Englishlanguage translations of foreign scientific and technical material pertinent to NASA's mission.

Specialized services also include creating custom thesauri, building customized databases, organizing and publishing research results.

For more information about the NASA STI program, see the following:

- Access the NASA STI program home page at http://www.sti.nasa.gov

- E-mail your question via the Internet to help@ sti.nasa.gov

- Fax your question to the NASA STI Help Desk at $443-757-5803$

- Telephone the NASA STI Help Desk at 443-757-5802

- Write to: NASA Center for AeroSpace Information (CASI) 7115 Standard Drive Hanover, MD 21076-1320 
NASA/TM-2012-217115

INA 21

Effect of Internal Clearance on Load

Distribution and Life of Radially Loaded Ball and Roller Bearings

Fred B. Oswald and Erwin V. Zaretsky

Glenn Research Center, Cleveland, Ohio

Joseph V. Poplawski

J.V. Poplawski \& Associates

Prepared for the

65th Annual Meeting and Exhibition

sponsored by the Society of Tribologists and Lubrication Engineers (STLE)

Las Vegas, Nevada, May 16-20, 2010

National Aeronautics and

Space Administration

Glenn Research Center

Cleveland, Ohio 44135 
Level of Review: This material has been technically reviewed by technical management.

Available from

NASA Center for Aerospace Information

7115 Standard Drive

Hanover, MD 21076-1320
National Technical Information Service 5301 Shawnee Road Alexandria, VA 22312

Available electronically at http://www.sti.nasa.gov 


\title{
Effect of Internal Clearance on Load Distribution and Life of Radially Loaded Ball and Roller Bearings
}

\author{
Fred B. Oswald and Erwin V. Zaretsky* \\ National Aeronautics and Space Administration \\ Glenn Research Center \\ Cleveland, Ohio 44135 \\ Joseph V. Poplawski \\ J.V. Poplawski \& Associates \\ Bethlehem, Pennsylvania 18018
}

\section{Summary}

The effect of internal clearance on radially loaded deepgroove ball and cylindrical roller bearing load distribution and fatigue life was determined for four clearance groups defined in the bearing standards. The analysis was extended to negative clearance (interference) conditions to produce a curve of life factor versus internal clearance. Rolling-element loads can be optimized and bearing life maximized for a small negative operating clearance. Life declines gradually with positive clearance and rapidly with increasing negative clearance. Relationships were found between bearing life and internal clearance as a function of ball or roller diameter, adjusted for load. Results are presented as life factors for radially loaded bearings independent of bearing size or applied load. In addition, a modified Stribeck Equation is presented that relates the maximum rolling-element load to internal bearing clearance.

\section{Introduction}

When a ball or roller bearing is subjected to a radial load, the rolling elements making up the bearing assembly are not equally loaded. Usually, less than half of the rolling elements are loaded at any given time. The actual load on each rolling element depends on its position in the bearing (Ref. 1). In 1900, Stribeck (Ref. 2) investigated the variation of loads on the elements of a radially loaded ball bearing. Stribeck found that the load on the most heavily loaded ball is 4.37 times the average ball load for zero internal clearance. Stribeck recommended rounding his constant up to 5.0 to account for nonzero clearance and other effects (Ref. 2).

Palmgren (Ref. 3) states that the theoretical value of Stribeck's constant for roller bearings at zero internal clearance is 4.08. Palmgren suggested using the Stribeck (Ref. 2) recommended value of 5.0 for the Stribeck constant for either ball or roller bearings having typical clearance.

Radially loaded rolling-element bearings often require a small internal clearance to accommodate interference fits and thermal strain. In addition, clearance is introduced by wear in the bearing. The American National Standards Institute/American Bearing Manufacturers Association (ANSI/ABMA) Standard 20
(Ref. 4), the corresponding ISO Standard (ISO 5753 (Ref. 5)), and catalogs of bearing manufacturers specify five groups of internal diametral clearances for bearings of different sizes. These clearance groups are designated 2, N (or "normal"), 3, 4, and 5.

The load distribution among the rolling elements varies for different amounts of diametral clearance. Bearing internal clearances can significantly increase or decrease the rollingelement fatigue life of a radially loaded ball or roller bearing. The Lundberg-Palmgren life equations (Refs. 6 to 7 ) for radially loaded bearings are based on zero internal clearance and the Stribeck formula (Ref. 2). However, because of shaft/bore interference fits and thermal effects, the mounted operating diametral clearance of a bearing with an initial clearance of zero can be negative.

Sadeghi et al. (Ref. 8) gives an overview of rolling-element fatigue modeling including a discussion of the physical mechanisms of fatigue and the limitations of various models.

Elmidany et al. (Ref. 9) performed an analytical study of the effect of internal interference, reporting that moderate interference (negative clearance) improves bearing life and rigidity and reduces noise. However, it may be prudent engineering practice to operate a radially loaded bearing with a small positive diametral clearance to prevent a significant decrease in the bearing fatigue life or even seizure due to thermal effects.

Harris (Ref. 10) and Harris and Kotzalas (Ref. 11) show that preloading through a moderate interference fit improves load distribution, prevents rolling-element skidding, and can increase fatigue life. Harris and Kotzalas (Ref. 11), based on earlier work by Sjövall (Ref. 12), Palmgren (Ref. 3), and Lundberg and Palmgren (Refs. 6 to 7), provide a table for the load-distribution integral $J_{r}$ in terms of the load-zone parameter $\varepsilon$ (which they call the load-distribution factor). The Stribeck constant should equal the reciprocal of $J_{r}$. At zero clearance, where the load zone is $180^{\circ}, \varepsilon=0.5$. Then $1 / J_{r}=$ 4.37 for ball bearings with point contact and $1 / J_{r}=4.08$ for roller bearings with line contact.

Jones (Refs. 13 and 14) and Houpert (Ref. 15) present an analysis for bearing rolling-element loads for bearings with a nonzero contact angle and with loads involving displacements in 5 degrees of freedom.

*Distinguished Research Associate. 
Houpert (Ref. 16) found values of 1.074 and 1.078 for the load-deflection exponent for line contact on the inner and outer races, respectively, of a roller bearing rather than the accepted value of $10 / 9=1.1$ or 1.11 (Lundberg and Palmgren, Ref. 7) or the earlier value of 1.0 (Lundberg and Palmgren, Ref. 6).

From the preceding discussion, the objectives of the work reported herein are (1) to investigate the effect of internal bearing clearance on rolling-element loading and the resultant bearing fatigue life for deep-groove ball bearings and cylindrical roller bearings operating at low speed, and (2) to develop a fatigue life relation for these bearings that incorporates internal bearing clearance, static radial load capacity, rolling-element diameter, and applied radial load.

Symbols are defined in Appendix A.

\section{Stribeck's Load-Distribution Factor at Zero Internal Clearance}

\section{Load Distribution and Maximum Load in Radially Loaded Ball Bearings}

A representative deep-groove ball bearing is shown in Figures 1(a) and (b). The bearing comprises an inner and outer ring and a plurality of balls interspersed between the two rings and positioned by a cage or separator. The internal diametral clearance $G_{r}$ is indicated on the figure. A cylindrical roller bearing is similar except that the rolling elements are cylinders and typically there are no shoulders on the inner race.

In 1900, Stribeck (Ref. 2) investigated the variation of loads on the elements of a ball bearing to calculate the frictional forces. When a ball or roller bearing is subjected to a radial load, the rolling elements are not equally loaded. The load zone for a radially loaded bearing with internal clearance will be less than $\pi / 2\left(180^{\circ}\right)$.

Figure 2 (from Anderson, Ref. 1) shows part of a ball bearing with zero internal clearance that has $z=12$ balls oriented such that the load path passes through ball 1 . For this bearing oriented as shown, five balls carry the load: ball 1 plus two more pairs. The parameter $n$ designates the number of pairs of balls carrying load in addition to ball 1; thus in Figure 2, $n=2$. In general, $n$ can be found from Equation (1), where INT, the integer function, means that any fractional part in Equation (1) is truncated, and $z$ is the number of rolling elements.

$$
n=I N T\left(\frac{z-1}{4}\right)
$$

The angle $\beta$ between the rolling elements is given by

$$
\beta=\frac{2 \pi}{z}
$$

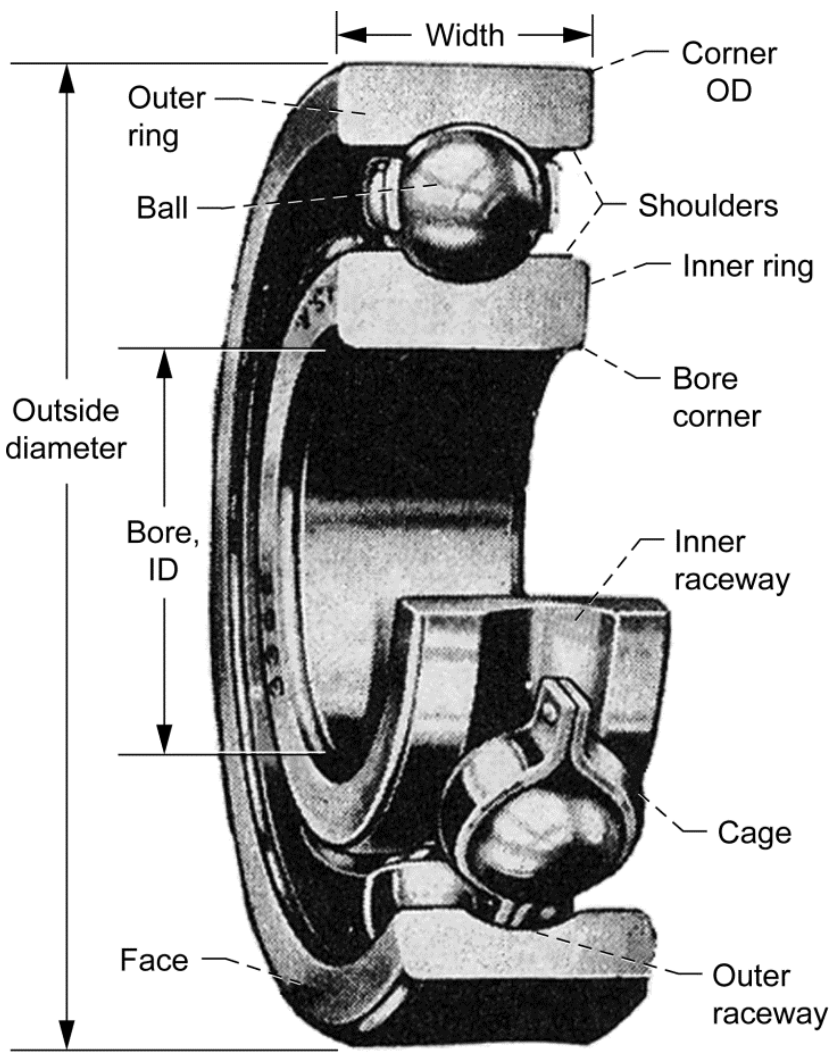

(a)

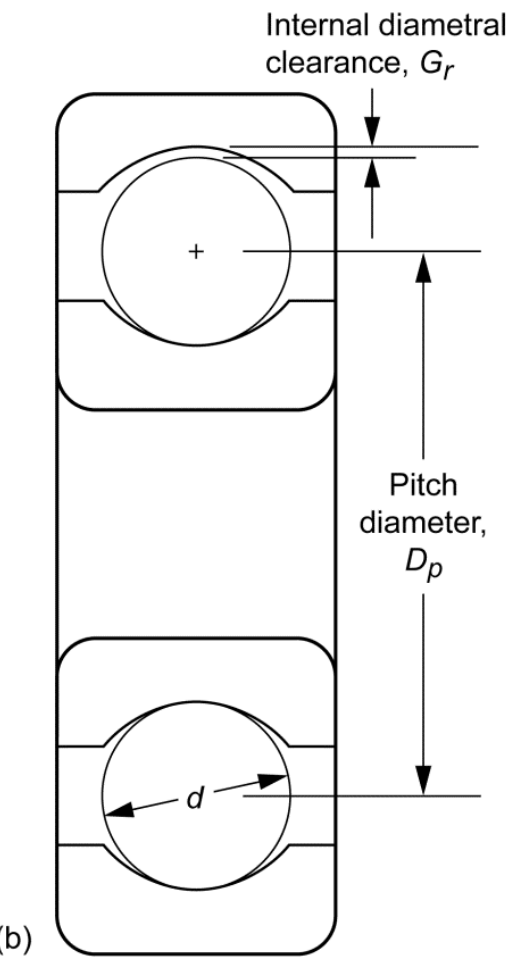

Figure 1.-Deep-groove ball bearing details. (a) Sketch. (b) Cross section showing internal diametral clearance. 


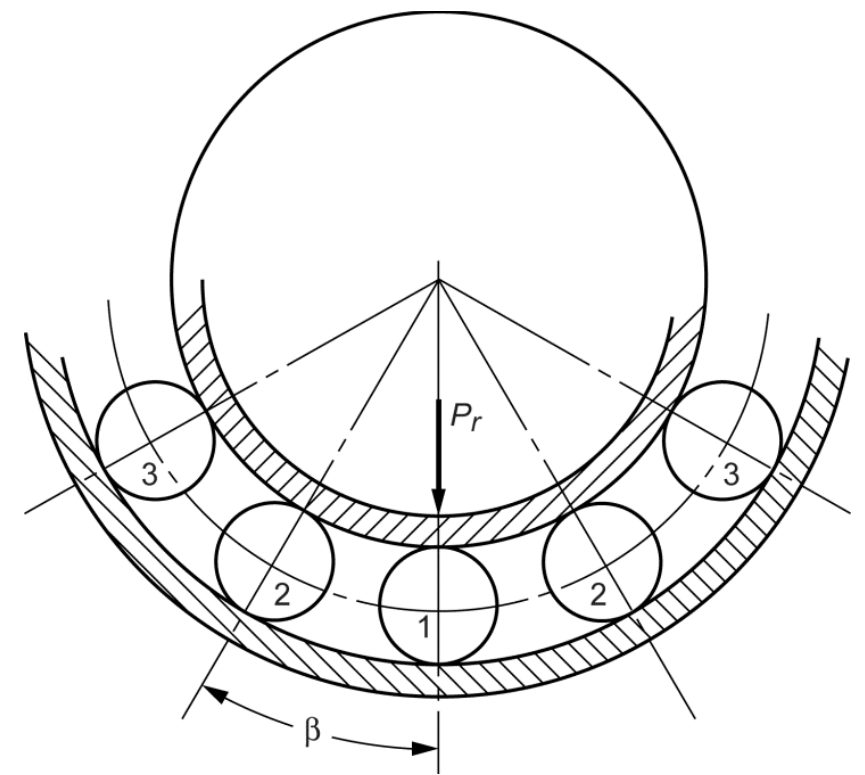

Figure 2.-Geometry to calculate distribution of ball load, $P_{r}$, in radially loaded ball bearing at zero clearance. Adapted from Anderson (Ref. 1).

For static equilibrium of a radially loaded ball bearing with zero internal clearance, the ball loads are given by (Ref. 1):

$$
P_{r}=P_{1}+2 P_{2} \cos \beta+2 P_{3} \cos 2 \beta+\ldots+2 P_{n+1} \cos n \beta
$$

where $P_{r}$ is the applied radial load on the bearing and $P_{1}, P_{2}, \ldots P_{n+1}$ are loads on individual rolling elements. The normal-direction approach between two surfaces for a ball on a raceway (point contact) is proportional to $P_{r}^{2 / 3}$ (Ref. 3), thus the ratio of deflection/load between rolling element 1 and the race and rolling element 2 and the same race under load is

$$
\frac{\delta_{2}}{\delta_{1}}=\left(\frac{P_{2}}{P_{1}}\right)^{2 / 3}
$$

or

$$
\frac{P_{2}}{P_{1}}=\left(\frac{\delta_{2}}{\delta_{1}}\right)^{3 / 2}
$$

In addition,

$$
\delta_{j}=\delta_{1} \cos j \beta
$$

for $j=2,3, \ldots n+1$, as long as the races remain circular, where $j$ is the number of pairs of balls or rollers. Therefore,

$$
P_{j}=P_{1}\{\cos [(j-1) \beta]\}^{3 / 2}
$$

The loads on the rolling elements are found by combining Equations (1) to (7). Stribeck found that, for zero clearance, $Q$ (the quantity in brackets in Eq. (8a)) is very nearly the constant 4.37 divided by $z$, the number of balls (i.e., $z / Q=4.37$ ).

$$
\begin{gathered}
P_{r}=P_{1}\left[1+2(\cos \beta)^{5 / 2}+2(\cos 2 \beta)^{5 / 2}+\ldots+2(\cos n \beta)^{5 / 2}\right] \\
P_{r}=P_{1}[Q]
\end{gathered}
$$

Because $P_{1}$ is the maximum ball load $P_{\max }$, Equation (8b) becomes

$$
P_{r}=P_{\max } Q
$$

and thus the maximum ball load for zero clearance on a radially loaded, deep-groove ball bearing is proportional to the ratio of the applied load to the number of balls in the bearing. The constant of proportionality is called the Stribeck Number $S_{t}$ :

$$
P_{\text {max }}=\frac{P_{r}}{Q}=\frac{S_{t} P_{r}}{z}
$$

where

$$
S_{t}=\frac{z}{Q}=\frac{P_{\max }}{P_{r} / z}
$$

Note that $P_{r} / z$ in the denominator is the average ball or roller load.

The Stribeck analysis was for zero diametral clearance and did not include the effects of internal fit up or inertia. The Stribeck Number will vary with internal clearance, fit up, race distortion, and load (Ref. 13). To account for these effects and possible noncircularity of the balls and the races, Stribeck (Ref. 2) suggested rounding his constant $z / Q$ up to 5.0.

\section{Load Distribution and Maximum Load in Cylin- drical Roller Bearings}

Palmgren (Ref. 3) stated that the theoretical value of Stribeck's zero-clearance constant will be 4.08 and suggested using Stribeck's rounded-up value for the Stribeck Number $S_{t}=5.0$ (Ref. 2) for either ball or roller bearings having typical clearance.

The derivation for the maximum loaded roller in a cylindrical roller bearing is similar to what is shown in the preceding section for ball bearings. The normal approach between two surfaces in line contact is proportional to $P_{r}^{0.9}$ (Ref. 3). Thus Equation (5) for roller bearings becomes

$$
\frac{P_{2}}{P_{1}}=\left(\frac{\delta_{2}}{\delta_{1}}\right)^{1 / 0.9}=\left(\frac{\delta_{2}}{\delta_{1}}\right)^{1.11}
$$


TABLE I.-CALCULATION OF THE STRIBECK NUMBER, $S_{t}=Z / Q$, FOR BALL AND ROLLER BEARINGS AT ZERO CLEARANCE

\begin{tabular}{|c|c|c|c|c|c|c|c|c|}
\hline \multirow{2}{*}{$\begin{array}{l}\text { Number of } \\
\text { balls or } \\
\text { rollers, } \\
z\end{array}$} & \multirow{2}{*}{$\begin{array}{c}\text { Ball or } \\
\text { roller angle, } \\
\beta, \\
\text { deg }\end{array}$} & \multirow{2}{*}{$\begin{array}{l}\text { Value of } n \\
\text { in } \\
\text { Equation } \\
\text { (1) }\end{array}$} & \multicolumn{3}{|c|}{ Radial ball bearings } & \multicolumn{3}{|c|}{ Cylindrical roller bearings } \\
\hline & & & $\begin{array}{c}\text { Load } \\
\text { distribution } \\
\text { factor, } \\
Q\end{array}$ & $\begin{array}{l}\text { Stribeck } \\
\text { Number }\end{array}$ & $\begin{array}{c}\text { Error in } S_{t} \text {, } \\
\text { percent }\end{array}$ & $\begin{array}{c}\text { Load } \\
\text { distribution } \\
\text { factor, } \\
Q\end{array}$ & $\begin{array}{l}\text { Stribeck } \\
\text { Number }\end{array}$ & $\begin{array}{c}\text { Error in } S_{t} \text {, } \\
\text { percent }\end{array}$ \\
\hline 3 & 120 & 0 & 1.000 & 3.00 & 31.4 & 1.000 & 3.000 & 26.5 \\
\hline 4 & 90 & 0 & 1.000 & 4.00 & 8.5 & 1.000 & 4.000 & 2.1 \\
\hline 5 & 72 & 1 & 1.106 & 4.52 & -3.4 & 1.168 & 4.281 & -4.8 \\
\hline 6 & 60 & 1 & 1.354 & 4.43 & -1.4 & 1.463 & 4.100 & -.4 \\
\hline 7 & 51.43 & 1 & 1.614 & 4.34 & .7 & 1.738 & 4.027 & 1.4 \\
\hline 8 & 45 & 1 & 1.841 & 4.35 & .6 & 1.963 & 4.076 & .2 \\
\hline 9 & 40 & 2 & 2.052 & 4.39 & -.3 & 2.189 & 4.111 & -.7 \\
\hline 10 & 36 & 2 & 2.284 & 4.36 & -.2 & 2.447 & 4.087 & -.1 \\
\hline 20 & 18 & 4 & 4.578 & 4.37 & .0 & 4.898 & 4.084 & .0 \\
\hline 30 & 12 & 7 & 6.865 & 4.37 & .0 & 7.345 & 4.084 & .0 \\
\hline 50 & 7.2 & 12 & 11.441 & 4.37 & .0 & 12.242 & 4.084 & .0 \\
\hline
\end{tabular}

Equation (7) for $j=2,3, \ldots n+1$ becomes

$$
P_{j}=P_{1}\{\cos [(j-1) \beta]\}^{1.11}
$$

and Equation (8a) applied to roller bearings becomes

$$
\begin{gathered}
P_{r}=P_{1}\left[1+2(\cos \beta)^{2.11}+2(\cos 2 \beta)^{2.11}+\ldots+2(\cos n \beta)^{2.11}\right] \\
P_{r}=P_{1}[Q]=P_{\max } Q
\end{gathered}
$$

Note that the $Q$ for roller bearings in Equation (14b) differs from the $Q$ for ball bearings in Equation (8b).

Table I shows several values of the calculated $z / Q$ for various numbers of balls and rollers. The error (difference from Stribeck's value of 4.37) for ball bearings is less than 1 percent if there are at least seven balls in the bearing. Likewise, for roller bearings, $z / Q$ converges to 4.08 with an error of less than 1 percent if there are at least eight rollers in the bearing. The value 4.08 is 6.5 percent less than the Stribeck Number for ball bearings.

If the load-deflection exponent in Equation (12) is taken as 1.0 (as in Lundberg and Palmgren's 1947 paper (Ref. 6), rather than as 1.1 (as in their 1952 paper, Ref. 7), then $z / Q$ for roller bearings converges to 4.0. However, later work such as Palmgren (Ref. 3) states that the deflection is proportional to $P^{0.9}$, where there is line contact on both races. Thus, the load-deflection exponent $\alpha$ in Equation (12) should be 10/9 (typically rounded to 1.11).

\section{Effect of Internal Clearance on Rolling- Element Load Distribution}

\section{Computer Analysis}

The loads between the rolling elements and the inner and outer races of a bearing are shown schematically in Figure 3. The initial radial clearance is shown in Figure 4(a). The compression in the normal direction of element $j$ due to inner-ring displacement in a radially loaded ball or roller bearing is

$$
\delta_{n j}=\Delta_{x} \sin \psi_{j}+\Delta_{y} \cos \psi_{j}-\frac{G_{r}}{2}>0
$$

where $\Delta$ is the displacement of the inner race and $\psi_{j}$ is the position angle of element $j$. A more general treatment, including nonzero contact angle and loading in 5 degrees of freedom is presented by Jones (Refs. 13 and 14) and Houpert (Ref. 15).

The total compression $\delta_{n j}$ at rolling element $j$ is the sum of the deflections at the inner and outer race contacts:

$$
\delta_{n j}=\delta_{o j}+\delta_{i j}
$$

From the force equilibrium on an element,

$$
P_{i j}+C F_{j}-P_{o j}=0
$$

where

$$
\begin{gathered}
P_{i j}=K_{i j} \delta_{i j}^{\alpha} \\
P_{o j}=K_{o j} \delta_{o j}^{\alpha} \\
C F_{j}=k_{1} m_{j}\left(\frac{D_{p}}{2}\right) \omega_{\text {cage }}^{2}
\end{gathered}
$$




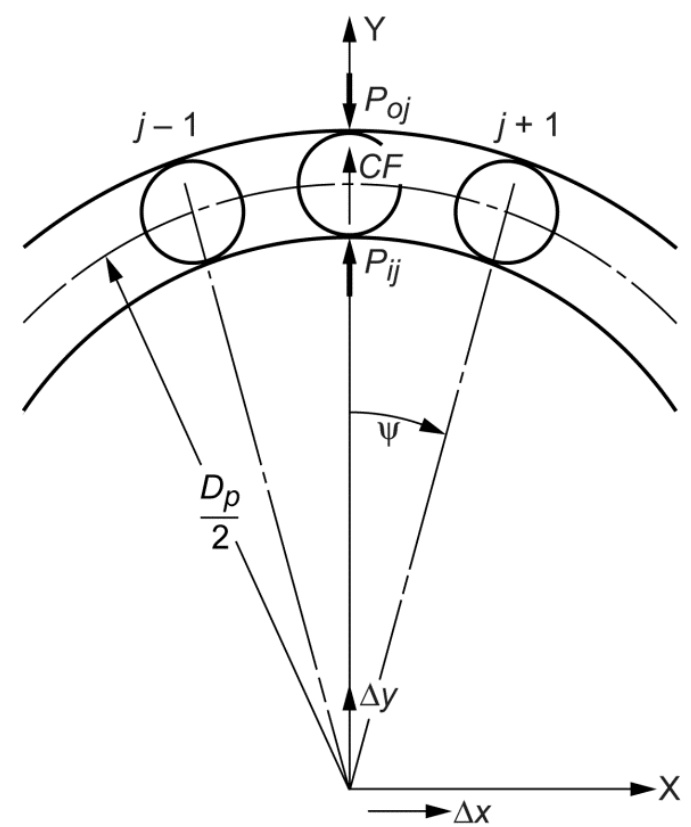

Figure 3.-Loads, $P$, and deflections between rolling elements and races in radially loaded ball or roller bearings. $D_{p}$, bearing pitch diameter; $j$, rolling-element number (index); $C F$, body force due to centripetal motion.

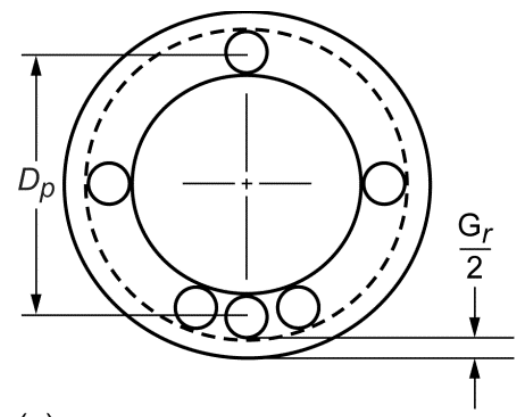

(a)

(b)
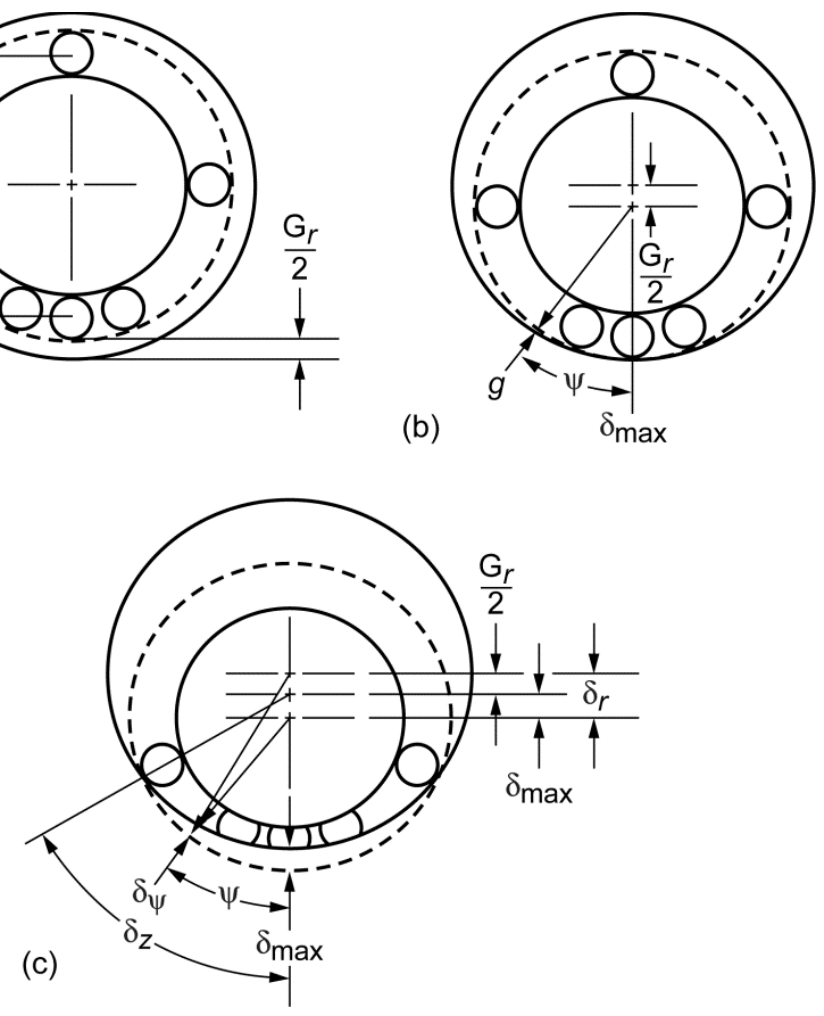

Figure 4.-Radially loaded rolling-element bearing. $G_{r}$, internal diametral clearance; $g$, radial clearance; $\delta_{\max }$, maximum race deformation. (a) Concentric arrangement. (b) Initial contact. (c) Interference. Adapted from Hamrock and Anderson (Ref. 17). 
and where $K$ is the stiffness, $k_{1}$ is the body-force conversion constant, $D_{p}$ is the bearing pitch diameter, $m$ is the mass, and $\omega$ is the rotating speed.

Exponent $\alpha=10 / 9 \approx 1.11$ for line contact in a roller bearing and $\alpha=3 / 2$ for point contact in a ball bearing. For units of newtons, kilograms, and millimeters, the body-force conversion constant $k_{1}=10^{-6}$, and for units of pounds and inches, $k_{1}=0.00259$.

The roller-race stiffness in a roller bearing can be found from Equation (20a), where $l_{e}$ is the equivalent roller length and $E^{\prime}$ is the effective elastic modulus. The ball-race stiffness in a radial ball bearing is given in Equations (20b) and (20c), where $\varepsilon(\alpha)$ is the elliptic integral of the second kind, $R$ is the effective radius of curvature, and $\mathfrak{I}(\alpha)$ is the elliptic integral of the first kind. Appendixes $\mathrm{B}$ and $\mathrm{C}$ provide derivations for Equations (20a) to (20c). These expressions are valid for both metric units ( $\mathrm{MPa}$ and $\mathrm{mm}$ ) and English units (lb and in.).

$$
\begin{gathered}
K_{i j} \approx K_{o j}=0.3555 \cdot E^{\prime} l_{e}^{1.11} \\
K_{i j}=\pi k_{i}(\alpha) E^{\prime} \sqrt{\frac{2 \mathcal{E}_{i}(\alpha) R_{i}}{9 \cdot \mathfrak{I}_{i}^{3}(\alpha)}} \\
K_{o j}=\pi k_{o}(\alpha) E^{\prime} \sqrt{\frac{2 \mathcal{E}_{o}(\alpha) R_{o}}{9 \cdot \mathfrak{I}_{o}^{3}(\alpha)}}
\end{gathered}
$$

The geometry parameters in Equations (20b) and (20c) are defined in the next section.

Combining Equations (16) and (18) to (20) with the equilibrium equation (Eq. (17)) gives

$$
K_{o j}\left(\delta_{n j}-\delta_{i j}\right)^{\alpha}-K_{i j} \delta_{i j}^{\alpha}-C F_{j}=0
$$

Equation (21) can be solved for $\delta_{i j}$ by iteration for an assumed deflection $\delta_{n j}$. Then $\delta_{o j}$ can be found from $\delta_{i j}$, and $P_{i j}$ and $P_{o j}$ can be found from Equation (18). The equilibrium between the applied radial loads and the estimated bearing reactions can be checked for a given $\Delta_{x}$ and $\Delta_{y}$ from Equations (22a) and (22b), where $F_{x}$ and $F_{y}$ are the applied radial load in the $\mathrm{x}$ and $\mathrm{y}$ directions and $\psi$ is the position angle from the maximum-loaded rolling element.

$$
\begin{aligned}
& F_{x}-\sum_{j=1}^{n} P_{i j} \sin \psi_{j}=\varepsilon_{x}^{\prime} \rightarrow 0 \\
& F_{y}-\sum_{j=1}^{n} P_{i j} \cos \psi_{j}=\varepsilon_{y}^{\prime} \rightarrow 0
\end{aligned}
$$

These equations are nonlinear and statically indeterminate. An iterative method, such as Newton-Rhapson as applied by Jones (Ref. 14) provides a stable and rapid solution.

The implementation of a computer solution, given the bearing geometry, internal clearance, speed, and set of applied forces is based on the following steps:

(1) Assume a starting value for the inner-race displacements $\Delta_{x}$ and $\Delta_{y}$

(2) Compute the compression $\delta_{n j}$ in the normal direction for each element using Equation (15)

(3) Solve Equation (21) by iteration for the compression $\delta_{i j}$ at the inner race contact for each element

(4) Compute the inner-race loads resulting from the compression at each element using Equation (18a)

(5) Check the equilibrium of forces using Equations (22a) and (22b)

(6) If the residual forces $\varepsilon_{x}^{\prime}$ and $\varepsilon_{y}^{\prime}$ are larger than a tolerance value, repeat steps 1 to 5 with new estimates for the inner-race displacements $\Delta_{x}$ and $\Delta_{y}$

Once this iteration has completed, $L_{10}$, the 10-percent fatigue life for the bearing, can be calculated using the classical Lundberg-Palmgren method (Refs. 6 and 7) from the rolling-element loads calculated above.

\section{Calculation of Maximum Rolling-Element Load by Approximate Method}

The geometry of a radially loaded ball or roller bearing with internal clearance is shown in Figure 4. Consider that the bearing is initially arranged symmetrically, with the clearance $G_{r}$ divided equally around the outer race (Fig. 4(a)).

Next, the clearance is taken up by an infinitesimal radial load that shifts the inner ring by a distance $G_{r} / 2$, as shown in Figure 4(b). Opposite the point of application of the radial load, the position angle $\psi=0^{\circ}$ and the clearance is zero. At any other (nonzero) angle $\psi$, there will be a radial clearance $g=(1-\cos \psi) G_{r} / 2$. At $\psi=90^{\circ}$, the clearance $g$ will be the initial value of $G_{r} / 2$.

Additional load applied to the bearing causes elastic deformation at the contact between the rolling elements and the races as shown in Figure 4(c). At $\psi=0^{\circ}$, the maximum deformation $\delta_{\max }$ adds to the clearance takeup $G_{r} / 2$. The total race displacement $\delta_{T}=\delta_{\max }+G_{r} / 2$. If the race maintains a circular shape, the elastic compression of the rolling elements is given by Equation (23). For $G_{r}>-2 \delta_{T}$, the limiting contact angle $\psi_{1}$ is given by Equation (24) (Ref. 17, where $\varepsilon=1 / 2-$ $G_{r} /\left(4 \delta_{T}\right)$.

$$
\delta_{\psi}=\delta_{T} \cos \psi-G_{r} / 2
$$




$$
\psi_{l}=\cos ^{-1}\left(\frac{G_{r} / 2}{\delta_{T}}\right)=\cos ^{-1}(1-2 \varepsilon)
$$

Harris and Kotzalas (Ref. 11) provide an iterative procedure to calculate the maximum rolling-element load in ball and roller bearings using the load-distribution integral, $J_{r}(\varepsilon)$. They provide a chart and table for calculating $J_{r}$ from estimated values of the load-zone parameter $\varepsilon$. The following text and equations provide a modified version of this procedure, and examples are given in Appendix D.

Figure 5 shows a modified version of the Harris and Kotzalas (Ref. 11) load-distribution integral chart augmented with additional data from Houpert (Ref. 15). The left part of Figure 5 shows $J_{r}$ for bearings with internal clearance where $\varepsilon \leq 0.5$ (zone of contact not more than $180^{\circ}$ ). The right part shows $J_{r}$ for bearings with interference, where $\varepsilon>0.5$ (zone of contact greater than $180^{\circ}$ ).

The data of Figure 5 were fitted to mathematical functions that allow estimating the load-distribution integral $J_{r}$. These functions are plotted in Figure 5. For roller bearings with line contact, the load-distribution integral $J_{r}(\varepsilon)$ can be computed from Equation (25):

$$
\begin{gathered}
J_{r}=0.3268 \varepsilon^{0.4023} \quad 0.1 \leq \varepsilon<0.5 \\
J_{r}=0.2451 \quad \varepsilon=0.5 \\
J_{r}=-0.0852 \varepsilon^{4}+0.5703 \varepsilon^{3}-1.3343 \varepsilon^{2} \\
+1.775 \varepsilon-0.0771 \quad 0.5<\varepsilon \leq 2.0
\end{gathered}
$$
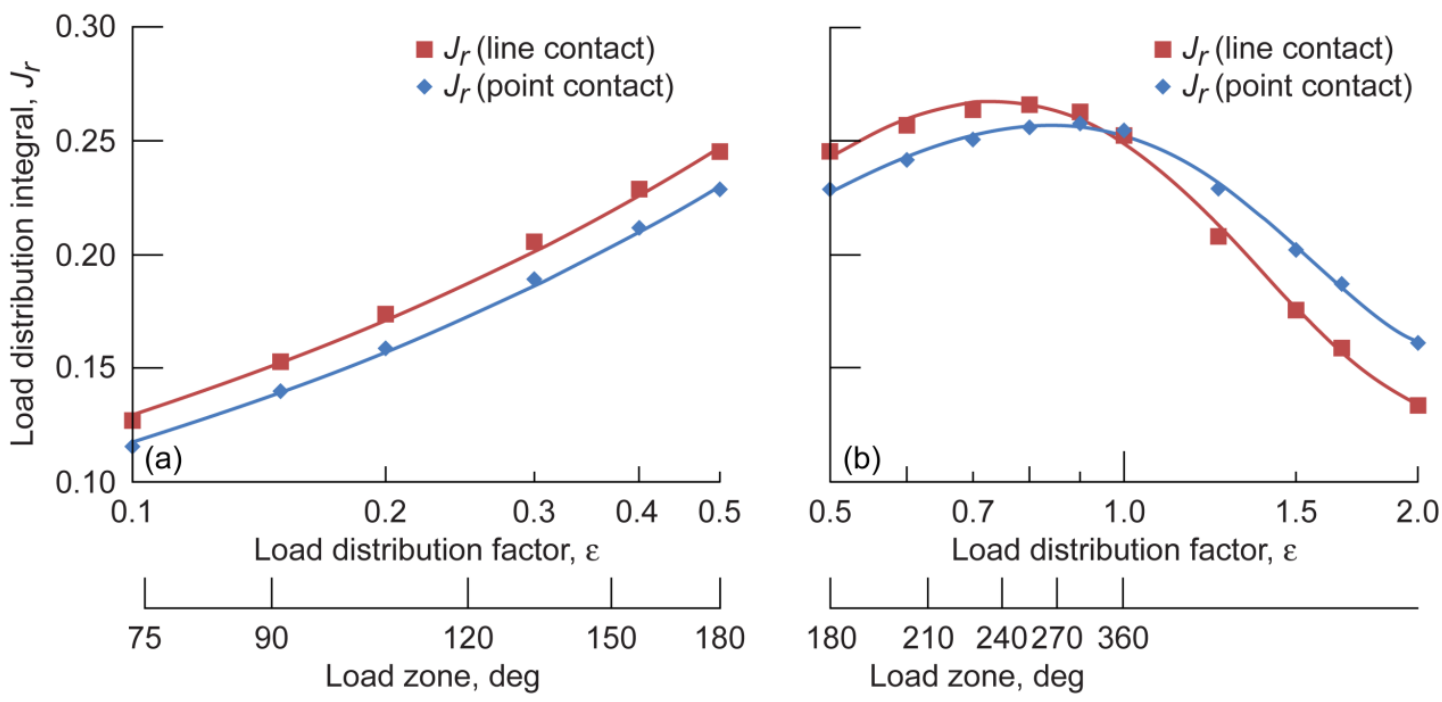

The Stribeck Number is computed from the reciprocal of the load-distribution integral, $S_{t}=1 / J_{r}(\varepsilon)$.

Estimating the load-distribution integral requires an expression for the bearing normal stiffness, which involves the combined deflection between the maximum-loaded rolling element and the two (inner and outer) races. The combined stiffness is given by

$$
K_{n}=\left[\left(1 / K_{i}\right)^{1 / n}+\left(1 / K_{o}\right)^{1 / n}\right]^{-n}
$$

where $n=1.11$ for roller bearings with line contact and $n=3 / 2$ for ball bearings with point contact.

For a roller bearing, the inner and outer race stiffnesses are nearly equal and can be computed from Equation (20a). Then Equations (20a) and (27) can be combined to find the normal stiffness $K_{n}$ :

$$
K_{n}=\frac{0.3555 E^{\prime} l_{e}^{8 / 9}}{2^{1.11}}=0.1647 E^{\prime} l_{e}^{8 / 9}
$$

Figure 5.-Load distribution integral versus load distribution factor for ball bearings with point contact and roller bearings with line contact. Data from Harris and Kotzalas (Ref. 11) and Houpert (Ref. 15). (a) $J_{r}$ for bearings with internal clearance where $\varepsilon \leq 0.5$ and the zone of contact $\leq 180^{\circ}$. (b) $J_{r}$ for bearings with interference, where $\varepsilon>0.5$ and the zone of contact $>180^{\circ}$. The rolling-element load zone is shown in a secondary scale. 
For a ball bearing, the inner and outer race stiffnesses needed for Equation (27) can be computed by Equations (20b) and $(20 \mathrm{c})$. These equations depend on several geometry parameters that must be calculated separately for the inner and outer races as shown in Equations (29) to (33).

The effective radii of curvature, $R_{i}$ and $R_{o}$ for the inner and outer ball-bearing races are given by

$$
\begin{aligned}
& R_{i}=\left[\frac{2 D_{p}}{d\left(D_{p}-d\right)}+\frac{2 f_{i}-1}{f_{i} d}\right]^{-1} \\
& R_{o}=\left[\frac{2 D_{p}}{d\left(D_{p}+d\right)}+\frac{2 f_{o}-1}{f_{o} d}\right]^{-1}
\end{aligned}
$$

where $d$ is the rolling-element diameter and $f$ is the race conformity.

Hamrock and Anderson (Ref. 17) give approximate expressions for the ellipticity parameter and elliptic integrals for a radially loaded ball bearing in terms of the radius ratios, $\alpha_{i}$ and $\alpha_{o}$. Coordinate axes $x$ and $y$ must be chosen such that both radius ratios are greater than 1 .

$$
\begin{aligned}
& \alpha_{i}=\frac{2 f_{i} D_{p}}{\left(D_{p}-d\right)\left(2 f_{i}-1\right)} \\
& \alpha_{o}=\frac{2 f_{o} D_{p}}{\left(D_{p}+d\right)\left(2 f_{o}-1\right)}
\end{aligned}
$$

Using the appropriate values of the radius ratio $\alpha$ for the inner and outer races yields the approximate ellipticity parameter $k(\alpha)$ and elliptic integrals $\mathfrak{I}(\alpha)$ and $\boldsymbol{\varepsilon}(\alpha)$ (Ref. 17):

$$
\begin{gathered}
k(\alpha) \approx(\alpha)^{2 / \pi} \\
\mathfrak{I}(\alpha) \approx \frac{\pi}{2}+\left(\frac{\pi}{2}-1\right) \ln (\alpha) \\
\mathcal{E}(\alpha) \approx 1+\frac{\pi / 2-1}{\alpha}
\end{gathered}
$$

The radial load on either a ball or roller bearing is given by Equation (34). Rearranging gives the total deflection $\delta_{T}$ in Equation (35).

$$
P_{r}=z K_{n}\left(\delta_{T}-G_{r} / 2\right)^{n} J_{r}(\varepsilon)
$$

$$
\delta_{T}=\frac{G_{r}}{2}+\left[\frac{P_{r}}{z K_{n} J_{r}(\varepsilon)}\right]^{1 / n}
$$

The total deflection $\delta_{T}$ is used to calculate the load-zone parameter, $\varepsilon=1 / 2-G_{r} /\left(4 \delta_{T}\right)$, which is then used for an updated estimate of the load-distribution integral $J_{r}(\varepsilon)$ from Equation (25) or (26).

The preceding equations can be used to find the Stribeck Number from the load-distribution integral. The equations are valid for either metric units ( $\mathrm{N}$ and $\mathrm{mm}$ ) or English traditional units ( $\mathrm{lb}$ and in.). The method is valid for zero, positive, and negative internal clearances in the bearing within the limits shown for the load-zone parameter $\varepsilon$.

Appendix D provides example calculations for a deepgroove ball bearing and a cylindrical roller bearing using the equations developed above to find the Stribeck Number from the load-distribution integral. The method is valid for zero, positive, and negative internal clearances in the bearing within the limits shown for the load-zone parameter $\varepsilon$. Either metric units ( $\mathrm{N}$ and $\mathrm{mm}$ ) or English traditional units ( $\mathrm{lb}$ and in.) may be used.

Appendix E shows a more direct alternative procedure based on Hamrock and Anderson (Ref. 17) that is valid for zero or positive clearance but not for negative clearance. Before these calculations are performed, the bearing internal clearance must be adjusted to account for thermal expansion, wear, and the effects of any interference fit between the bearing inner ring and shaft and between the outer ring and housing.

\section{Parametric Study-Effect of Internal Clearance on Bearing Load Distribution and Life}

A commercial bearing analysis code (Poplawski et al., Ref. 18) was used to determine the effect of internal clearance and interference on the distribution of load among the rolling elements and on the life of radially loaded deep-groove ball bearings and cylindrical roller bearings made from AISI 52100 steel. The code uses the traditional Lundberg-Palmgren method (Lundberg and Palmgren, Ref. 6). Each bearing was initially analyzed for the zero internal-clearance condition at three values of inner-race maximum Hertz stress: 1200, 1720, and $2240 \mathrm{MPa}(175,250$, and $325 \mathrm{ksi})$. These are designated light, normal, and heavy loads, respectively.

The radial load on each bearing was chosen to produce the desired stress at zero clearance. The same load was maintained as the internal clearance was varied over a range of positive and negative diametral clearances to examine the effect of clearance on bearing life and on the maximum ball or roller load. These clearance values are for net operating clearance 
including any effects from interference fit, thermal effects, and wear. The analysis was restricted to low speed, where inertial effects are not significant.

The properties (dimensions, static, and dynamic load capacity) of the deep-groove ball bearings analyzed in this article are given in Table II, and the properties of the cylindrical roller bearings are given in Table III. Ball bearings were modeled with both inner- and outer-raceway groove radius (conformity) of $0.52 d$, where $d$ is the ball diameter. Roller bearing rollers were modeled with an aerospace crown, with a flat length of 61.5 percent of the roller length and with the crown radius 100 times the roller length. The clearance values used in this analysis are shown in Tables IV and V for ball and roller bearings, respectively.

TABLE II.-DEEP-GROOVE BALL BEARING PROPERTIES

[Adapted from The Timken Company, Ref. 19.]

\begin{tabular}{|c|c|c|c|c|c|c|c|c|c|}
\hline \multirow[t]{2}{*}{$\begin{array}{c}\text { Bearing } \\
\text { size }\end{array}$} & \multirow[t]{2}{*}{$\begin{array}{c}\text { Bore, } \\
\mathrm{mm}\end{array}$} & \multirow[t]{2}{*}{$\begin{array}{l}\text { Outside } \\
\text { diameter, } \\
\mathrm{mm}\end{array}$} & \multirow[t]{2}{*}{$\begin{array}{c}\text { Number } \\
\text { of balls, } \\
z\end{array}$} & \multicolumn{2}{|c|}{$\begin{array}{l}\text { Ball diameter, } \\
d\end{array}$} & \multicolumn{2}{|c|}{$\begin{array}{c}\text { Static radial load } \\
\text { capacity, } \\
C_{o r}\end{array}$} & \multicolumn{2}{|c|}{$\begin{array}{c}\text { Dynamic radial load } \\
\text { capacity, } \\
C_{r} \\
\end{array}$} \\
\hline & & & & $\mathrm{mm}$ & in. & $\mathrm{N}$ & lbf & $\mathrm{N}$ & lbf \\
\hline 206 & 30 & 62 & 9 & 9.525 & $3 / 8$ & 11254 & 2530 & 19457 & 4374 \\
\hline 1910 & & 72 & 17 & 6.35 & $1 / 4$ & 11152 & 2507 & 13398 & 3012 \\
\hline 110 & & 80 & 12 & 9.525 & $3 / 8$ & 16610 & 3734 & 23291 & 5236 \\
\hline 210 & 50 & 90 & 10 & 12.7 & $1 / 2$ & 23162 & 5207 & 35083 & 7887 \\
\hline 310 & & 110 & 8 & 19.05 & $3 / 4$ & 37828 & 8504 & 61835 & 13901 \\
\hline 220 & 100 & 180 & 10 & 25.4 & 1 & 92639 & 20826 & 122161 & 27463 \\
\hline 1940 & 200 & 280 & 16 & 25.4 & 1 & 167360 & 37624 & 156573 & 35199 \\
\hline
\end{tabular}

TABLE III.-CYLINDRICAL ROLLER BEARING PROPERTIES

[Adapted from The Timken Company, Ref. 19.]

\begin{tabular}{|c|c|c|c|c|c|c|c|c|c|c|c|}
\hline \multirow[t]{2}{*}{$\begin{array}{c}\text { Bearing } \\
\text { size }\end{array}$} & \multirow[t]{2}{*}{$\begin{array}{c}\text { Bore, } \\
\mathrm{mm}\end{array}$} & \multirow[t]{2}{*}{$\begin{array}{l}\text { Outside } \\
\text { diameter, } \\
\text { mm }\end{array}$} & \multirow{2}{*}{$\begin{array}{l}\text { Number } \\
\text { of } \\
\text { rollers, } \\
z\end{array}$} & \multicolumn{2}{|c|}{$\begin{array}{c}\text { Roller } \\
\text { diameter, } \\
d\end{array}$} & \multicolumn{2}{|c|}{$\begin{array}{l}\text { Roller } \\
\text { length, } \\
L\end{array}$} & \multicolumn{2}{|c|}{$\begin{array}{c}\text { Static radial } \\
\text { load capacity, } \\
C_{o r}\end{array}$} & \multicolumn{2}{|c|}{$\begin{array}{c}\text { Dynamic radial } \\
\text { load capacity, } \\
C_{r} \\
\end{array}$} \\
\hline & & & & $\mathrm{mm}$ & in. & $\mathrm{mm}$ & in. & $\mathrm{N}$ & lbf & $\mathrm{N}$ & lbf \\
\hline 206 & 30 & 62 & 12 & 10 & 0.3937 & 10 & 0.3937 & 37632 & 8460 & 41035 & 9225 \\
\hline 1910 & & 72 & 20 & 7 & .2756 & 7 & .2756 & 32881 & 7392 & 29038 & 6528 \\
\hline 110 & & 80 & 18 & 9 & .3543 & 9 & .3543 & 49446 & 11116 & 44860 & 10085 \\
\hline 210 & 50 & 90 & 14 & 13 & .5118 & 13 & .5118 & 77226 & 17361 & 75464 & 16965 \\
\hline 310 & & 110 & 10 & 19 & .7480 & 19 & .7480 & 111010 & 24956 & 117273 & 26364 \\
\hline 220 & 100 & 180 & 14 & 25 & .9843 & 25 & .9843 & 295980 & 66539 & 259069 & 58241 \\
\hline 1940 & 200 & 280 & 26 & 24 & .9449 & 24 & .9449 & 553270 & 124380 & 361449 & 81257 \\
\hline
\end{tabular}

TABLE IV.- RADIAL BALL BEARING DIAMETRAL CLEARANCES [Adapted from ABMA, Ref. 4, and ISO, Ref. 5.]

\begin{tabular}{|c|c|c|c|c|c|c|c|c|}
\hline \multirow{3}{*}{$\begin{array}{c}\text { Bearing } \\
\text { bore } \\
\text { size, } \\
\mathrm{mm}\end{array}$} & \multicolumn{8}{|c|}{ Diametral clearance } \\
\hline & \multicolumn{2}{|c|}{ Group 2} & \multicolumn{2}{|c|}{ Group N } & \multicolumn{2}{|c|}{ Group 3} & \multicolumn{2}{|c|}{ Group 4} \\
\hline & $\begin{array}{l}\text { Minimum, } \\
\text { mm (in.) }\end{array}$ & $\begin{array}{c}\text { Maximum, } \\
\text { mm (in.) }\end{array}$ & $\begin{array}{l}\text { Minimum, } \\
\text { mm (in.) }\end{array}$ & $\begin{array}{c}\text { Maximum, } \\
\text { mm (in.) }\end{array}$ & $\begin{array}{l}\text { Minimum, } \\
\text { mm (in.) }\end{array}$ & $\begin{array}{c}\text { Maximum, } \\
\text { mm (in.) }\end{array}$ & $\begin{array}{l}\text { Minimum, } \\
\text { mm (in.) }\end{array}$ & $\begin{array}{c}\text { Maximum, } \\
\text { mm (in.) }\end{array}$ \\
\hline 30 & $0.001(0.00005)$ & $0.011(0.00045)$ & $0.005(0.0002)$ & $0.020(0.0008)$ & $0.013(0.0005)$ & $0.028(0.0011)$ & $0.023(0.0009)$ & $0.041(0.0016)$ \\
\hline 50 & $0.001(0.00005)$ & $0.011(0.00045)$ & $0.006(0.00025)$ & $0.023(0.0009)$ & $0.018(0.0007)$ & $0.036(0.0014)$ & $0.030(0.0012)$ & $0.051(0.0020)$ \\
\hline 75 & $0.001(0.00005)$ & $0.015(0.0006)$ & $0.010(0.0004)$ & $0.030(0.0012)$ & $0.025(0.0010)$ & $0.510(0.0020)$ & $0.046(0.0018)$ & $0.071(0.0028)$ \\
\hline 100 & $0.001(0.00005)$ & $0.018(0.0007)$ & $0.012(0.00045)$ & $0.036(0.0014)$ & $0.030(0.0012)$ & $0.058(0.0023)$ & $0.053(0.0021)$ & $0.084(0.0033)$ \\
\hline
\end{tabular}


TABLE V.-CYLINDRICAL ROLLER BEARING DIAMETRAL CLEARANCES

[Adapted from ABMA, Ref. 4, and ISO, Ref. 5.]

\begin{tabular}{|c|c|c|c|c|c|c|c|c|}
\hline \multirow{3}{*}{$\begin{array}{c}\text { Bearing } \\
\text { bore } \\
\text { size, } \\
\mathrm{mm}\end{array}$} & \multicolumn{8}{|c|}{ Diametral clearance } \\
\hline & \multicolumn{2}{|c|}{ Group 2} & \multicolumn{2}{|c|}{ Group N } & \multicolumn{2}{|c|}{ Group 3} & \multicolumn{2}{|c|}{ Group 4} \\
\hline & $\begin{array}{l}\text { Minimum, } \\
\text { mm (in.) }\end{array}$ & $\begin{array}{l}\text { Maximum, } \\
\text { mm (in.) }\end{array}$ & $\begin{array}{l}\text { Minimum, } \\
\text { mm (in.) }\end{array}$ & $\begin{array}{l}\text { Maximum, } \\
\text { mm (in.) }\end{array}$ & $\begin{array}{l}\text { Minimum, } \\
\text { mm (in.) }\end{array}$ & $\begin{array}{l}\text { Maximum, } \\
\text { mm (in.) }\end{array}$ & $\begin{array}{l}\text { Minimum, } \\
\text { mm (in.) }\end{array}$ & $\begin{array}{l}\text { Maximum, } \\
\text { mm (in.) }\end{array}$ \\
\hline 30 & $0(0)$ & $0.025(0.0010)$ & $0.020(0.0008)$ & $0.045(0.0018)$ & $0.035(0.0014)$ & $0.060(0.0024)$ & $0.050(0.0020)$ & $0.075(0.0030)$ \\
\hline 50 & $0.005(0.0002)$ & $0.035(0.0014)$ & $0.030(0.0012)$ & $0.060(0.0024)$ & $0.050(0.0020)$ & $0.080(0.0031)$ & $0.070(0.0028)$ & $0.100(0.0039)$ \\
\hline 75 & $0.010(0.0004)$ & $0.045(0.0018)$ & $0.040(0.0016)$ & $0.075(0.0030)$ & $0.065(0.0026)$ & $0.100(0.0039)$ & $0.090(0.0035)$ & $0.125(0.0049)$ \\
\hline 100 & $0.015(0.0006)$ & $0.050(0.0020)$ & $0.050(0.0020)$ & $0.085(0.0033)$ & $0.075(0.0030)$ & $0.110(0.0043)$ & $0.105(0.0041)$ & $0.140(0.0055)$ \\
\hline
\end{tabular}

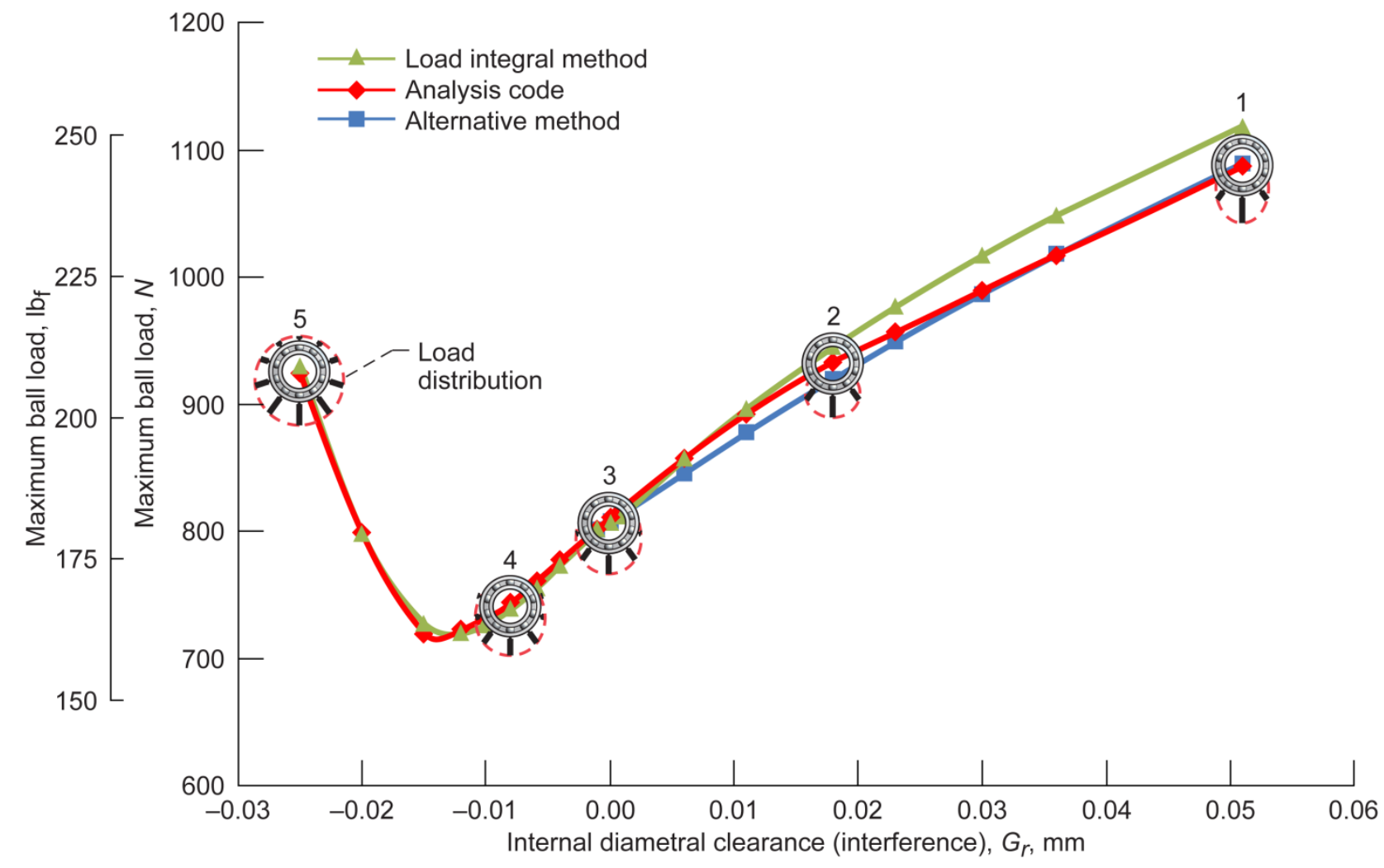

Figure 6.-Comparison of the effect of internal diametral clearance on maximum ball load for the bearing analysis code results and the two approximate methods presented in this article. Results are for 210-size, deep-groove ball bearings radially loaded to produce $1720-\mathrm{MPa}(250-\mathrm{ksi})$ inner-race maximum Hertz stress at zero clearance. Insets show bearing ball load distribution at five values of clearance.

\section{Variation of Rolling-Element Load Distribution With Internal Clearance}

Figure 6 shows the variation of maximum element (ball) load for zero, positive, and negative internal diametral clearance in a 210 -size radially loaded deep-groove ball bearing at normal load (1720 MPa maximum Hertz stress). Results are shown for three methods: (1) as computed by the bearing analysis code, (2) the load integral method, and (3) an alternative procedure described in Appendix E. The load integral method results were within 3.1 percent of the analysis code. The alternative method, which is restricted to nonnegative clearance, gave results within 1.7 percent of the analysis code. Similar results were obtained for cylindrical roller bearings.

Figure 6 includes small bearing diagrams to show the rolling-element (ball) load distribution at five clearance values. The ball loads shown were calculated by the analysis code (Ref. 18). The load distribution is discussed in the next section. 


\section{Life Factor for Internal Clearance}

The ratio of the life $L$ at any clearance condition, to the life at zero-clearance $L_{0}$ is designated the life factor $L F$ for that value of internal clearance of the bearing. By definition, the life factor equals 1.00 for zero clearance on any bearing.

$$
L F=\frac{L}{L_{0}}
$$

The four groups of diametral clearance investigated for 210 -size ball bearings are shown graphically in Figure 7. The clearance ranges from $0.001 \mathrm{~mm}$ (group 2, minimum), where $L F=0.99$, to $0.051 \mathrm{~mm}$ (group 4, maximum), where $L F=0.63$. There is also a group 5 clearance that we did not consider for this article.

Figure 7 shows the variation of life factor with internal diametral clearance for 210-size radially loaded deep-groove ball bearings at normal load, $1720 \mathrm{MPa}(250 \mathrm{ksi})$ maximum Hertz stress. The curve shows that increasing clearance results in reduced life. A small negative clearance (interference) of $-0.008 \mathrm{~mm}$ provides the greatest life factor found, 1.12. With greater interference, the life factor falls off rapidly, reaching 0.36 at -0.025 clearance because the maximum load has increased considerably.

The ball load diagrams (insets) of Figure 6 are also shown on Figure 7. Diagram 3 shows the ball loads at zero clearance, where five balls share the load and the life factor is defined to be 1.0. The greatest maximum ball load (diagram 1) occurs at the largest clearance $(0.051 \mathrm{~mm})$, where the load $P_{r}$ is shared by only three balls. The greatest life factor found, 1.12 , is shown in diagram 4, where seven balls carried the load. The smallest $P_{\max }$ (minimum point in the curves of Fig. 6) is at a slightly greater interference $(-0.013 \mathrm{~mm})$ than the maximum life factor condition shown in diagram 4. At the greatest negative clearance $(-0.025 \mathrm{~mm})$ shown (diagram 5), all 10 balls in the bearing share the load; however, the total load has increased significantly and the life factor is only 0.36 .

Note that the maximum life shown in Figure 7 occurs at a slightly smaller value of interference than the minimum load shown in Figure $6(0.008$ vs. $0.013 \mathrm{~mm})$. This is due to the effect of the increased loads on balls other than ball 1 (the ball carrying $P_{\max }$ ).

If the life factors for different loads or for different size bearings are plotted on the same axes, the curves will not match on the horizontal (clearance) axis. Figure 8 shows life factors for $50-\mathrm{mm}$ deep-groove ball bearings in four envelope sizes at the normal load condition, where, at zero clearance, the maximum Hertz stress is $1720 \mathrm{MPa}(250 \mathrm{ksi})$. The four bearing envelope sizes - designated "extremely light," "extra light," "light," and "medium" — are depicted schematically in the figure.

Internal bearing clearance values as specified in the ANSI/ABMA Standard 20 (Ref. 4) and ISO Standard, 5753 (Ref. 5) are given relative to the bearing bore diameter without consideration of any other bearing dimensions. However, as

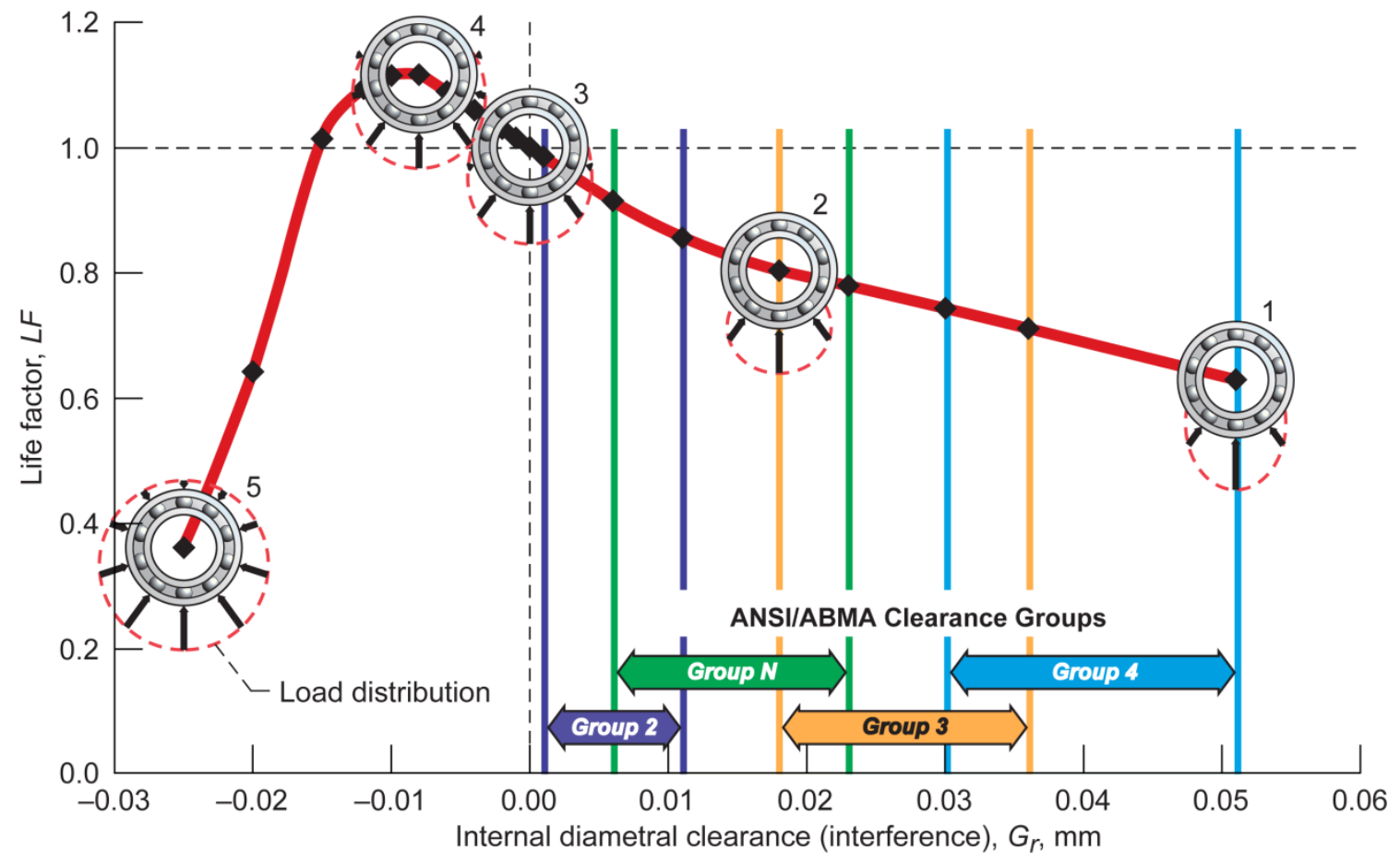

Figure 7.-Effect of internal diametral clearance on life factor for 210-size, deep-groove ball bearings radially loaded to produce 1720-MPa (250-ksi) inner-race maximum Hertz stress at the zero-clearance condition. Insets show bearing ball load distribution at five values of clearance. 


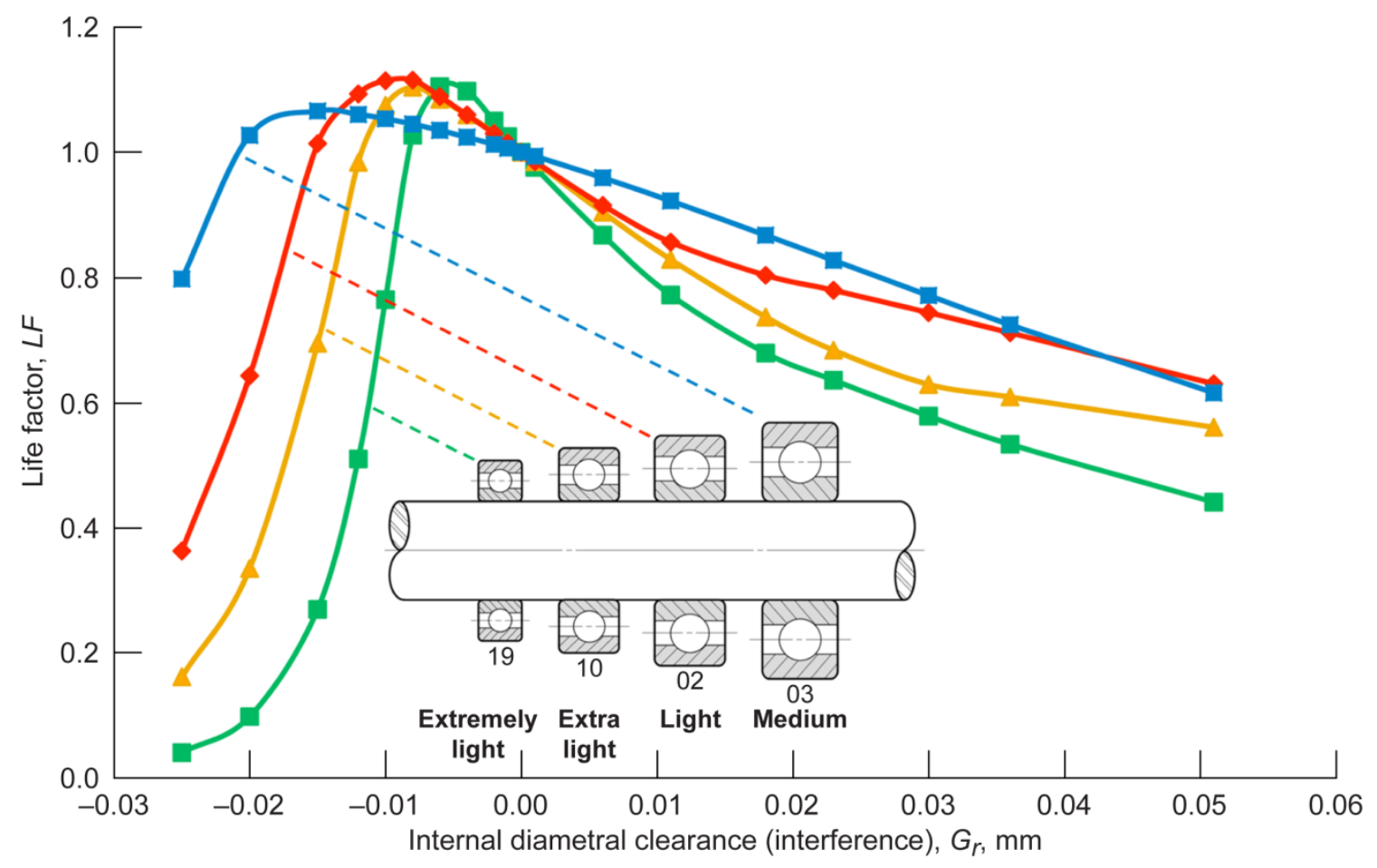

Figure 8.-Life factor versus internal diametral clearance in four envelope sizes of 50-mm deep-groove ball bearings radially loaded to produce $1720-\mathrm{MPa}(250-\mathrm{ksi})$ inner-race maximum Hertz stress at zero clearance (normal load condition).

can be seen in Figure 8, a given clearance has much more impact on the life of a small envelope bearing, such as "extremely light," than on the larger sizes, such as "medium."

With the clearance values in Figure 8 adjusted relative to the ball size, the curves closely match. Figure 9 shows the result of this adjustment, where the clearance is made dimensionless by dividing the actual clearance $G_{r}$ by the ball diameter $d$ to produce the nondimensional clearance $G_{r}^{\prime}$. If an adjustment is made relative to the bearing bore size or pitch diameter, rather than to the rolling-element diameter, the curves will not match.

$$
G_{r}^{\prime}=\frac{G_{r}}{d}
$$

Where initial (or unmounted) bearing clearance is needed to accommodate inner-ring expansion due to interference fits or thermal strain, it is correct to base such clearance on the bore diameter. However, ANSI/ABMA Standard 20 (Ref. 4) and ISO Standard, 5753 (Ref. 5), the bearing standards that relate recommended clearance on the bore diameter, must be used with care to avoid excessive operating clearance.

In Figure 9, the bearings all carry the same normal load (as defined earlier). If the applied radial load varies as shown in Figure 10, the life factor $L F$ curves will no longer match. However, applying a further adjustment, shown in Figure 11, will bring the curves back into alignment.
The adjustment involves multiplying the nondimensional clearance $G_{r}^{\prime}$ by the reciprocal of the maximum Hertz stress ratio squared: $\left(S_{\max }^{\prime} / S_{\max }\right)^{2}$, where $S_{\max }$ is the maximum innerring Hertz stress at zero clearance and $S_{\max }^{\prime}$ is the reference inner-race maximum Hertz stress: $1720 \mathrm{MPa}(250 \mathrm{ksi})$. This load-adjusted, nondimensional clearance is called the dimensionless internal diametral clearance number, $\hat{G}_{r}$.

$$
\hat{G}_{r}=\frac{G_{r}}{d}\left(\frac{S_{\max }^{\prime}}{S_{\max }}\right)^{2}
$$

Figure 12 shows the result of plotting $L F$ versus $\hat{G}_{r}$ for seven different sizes of deep-groove ball bearings at normal load. There are also curves for light and heavy loads for the 210 -size bearings. The maximum $L F=1.12$ for deep-groove ball bearings occurs with a small amount of negative clearance at $\hat{G}_{r}=-0.00099$.

Equation (38) requires solving for the maximum Hertz stress at zero clearance $S_{\max }$. The following text and equations present a simple procedure for calculating $\hat{G}_{r}$ without calculating $S_{\max }$. This procedure requires only the reference value of maximum Hertz stress $S_{\max }^{\prime}$, the bearing clearance $G_{r}$, the rolling-element diameter $d$, the static radial load capacity $C_{o r}$, and the radial load on the bearing $P_{r}$.

The maximum Hertz stress at zero clearance $S_{\max }$ can be found through a simple relation involving the applied load and the static radial load capacity as given in a bearing catalog. 


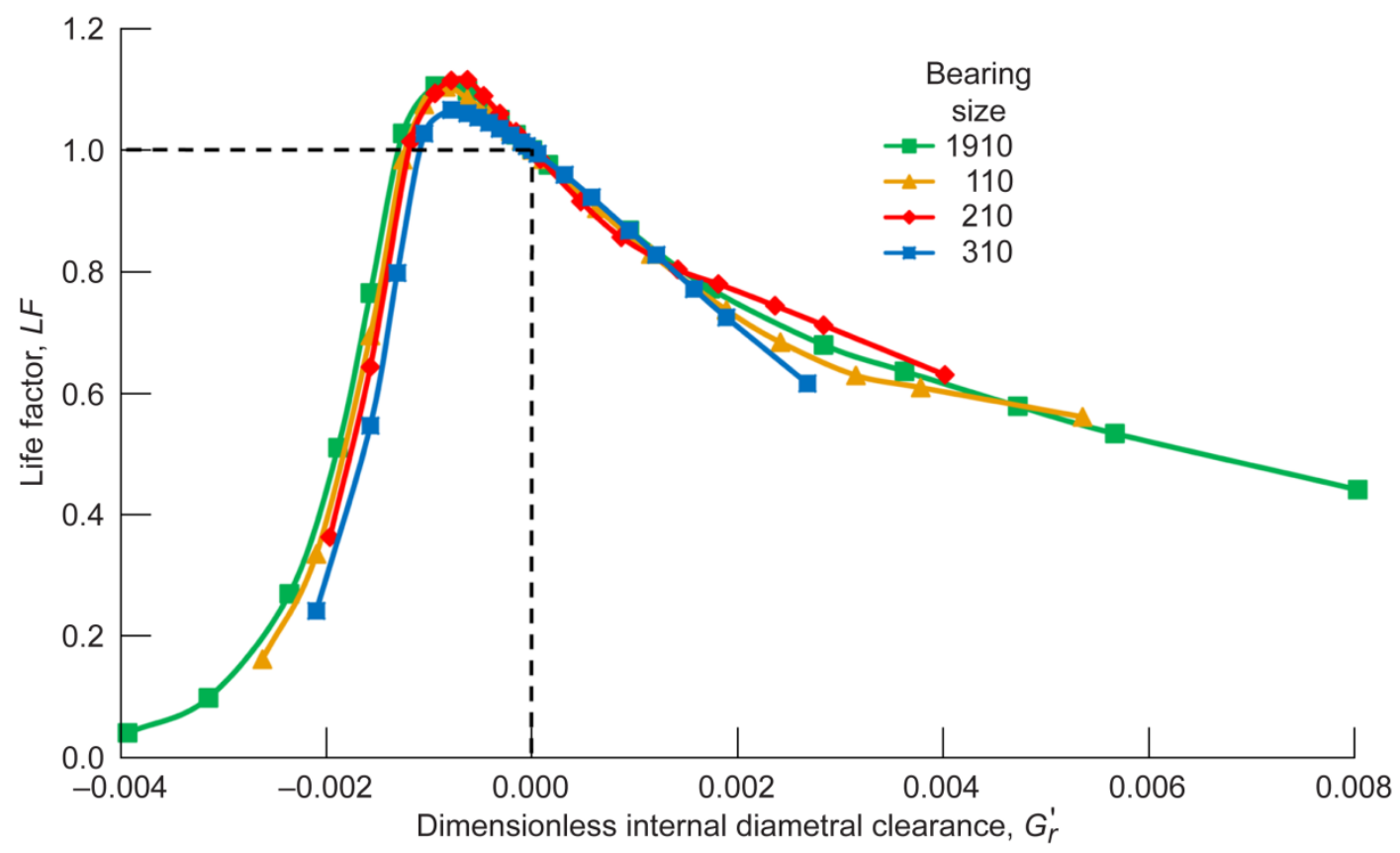

Figure 9.-Life factor versus dimensionless internal diametral clearance in four envelope sizes of 50-mm deep-groove ball bearings radially loaded to produce $1720-\mathrm{MPa}(250-\mathrm{ksi})$ inner-race maximum Hertz stress at zero clearance (normal load condition).

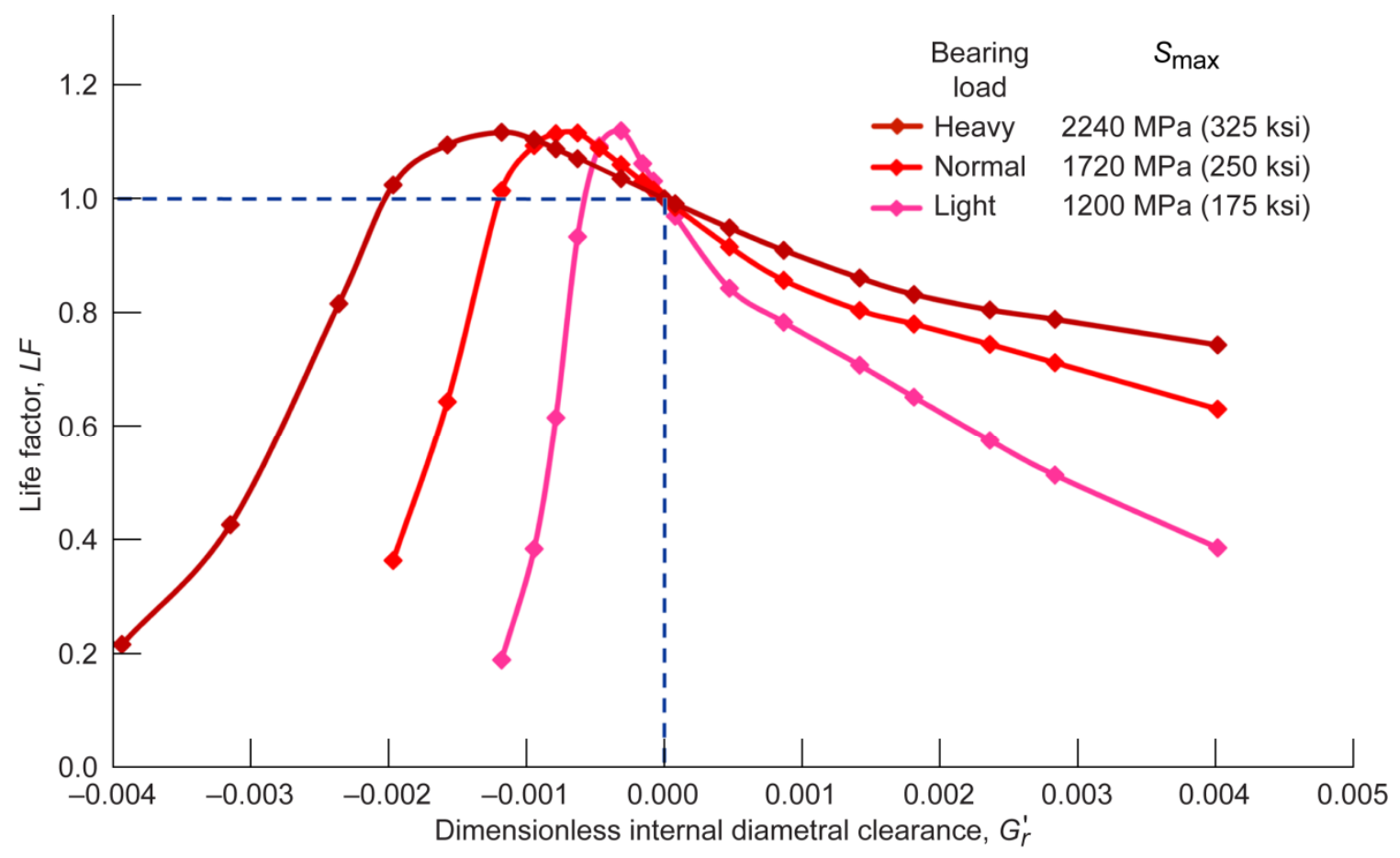

Figure 10.-Life factor versus dimensionless internal diametral clearance in 210-size deep-groove ball bearings at three loads and three corresponding levels of maximum Hertz stress, $S_{\max }$. 


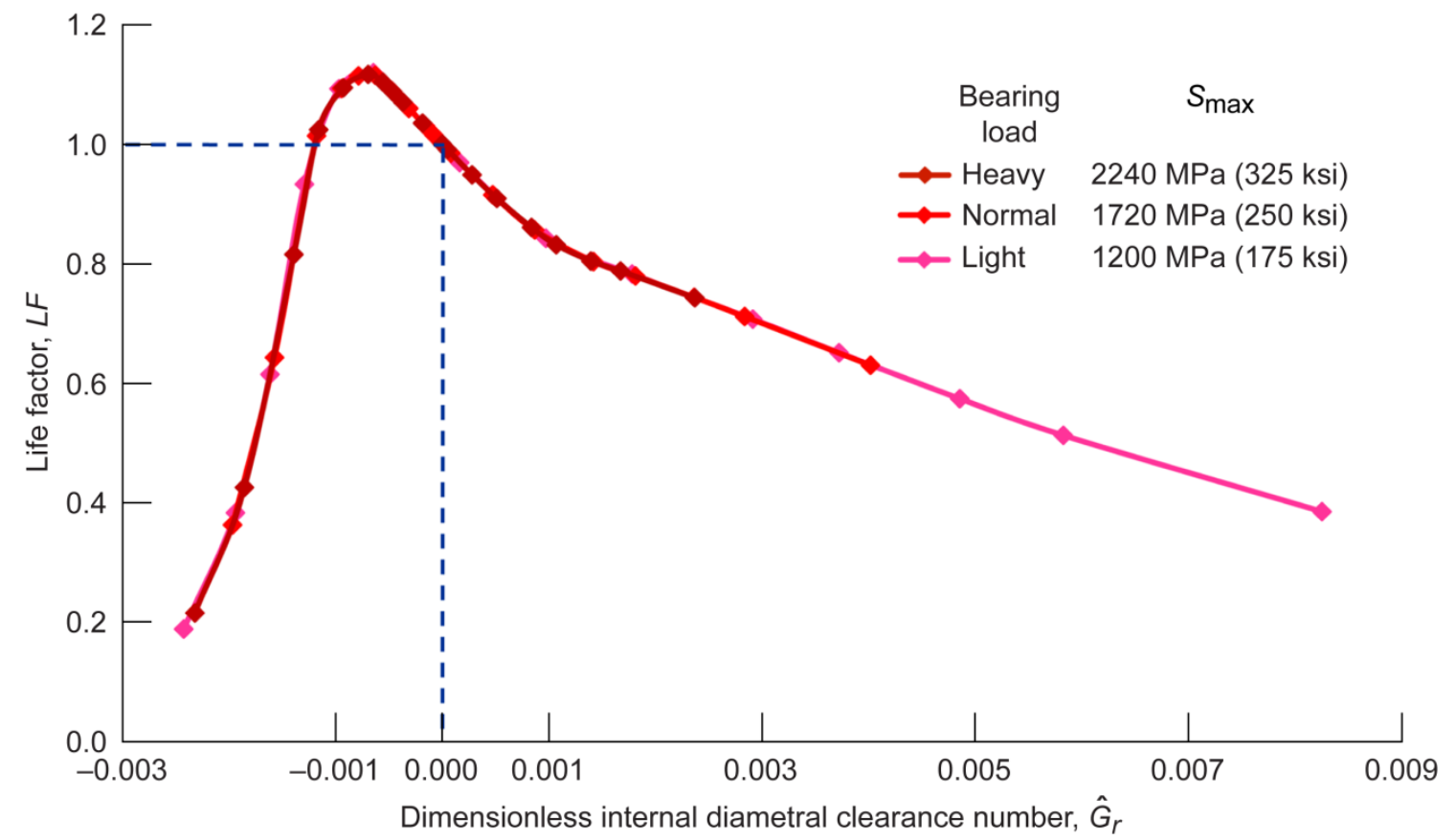

Figure 11.-Life factor versus dimensionless internal diametral clearance number in 210-size deep-groove ball bearings at three loads.

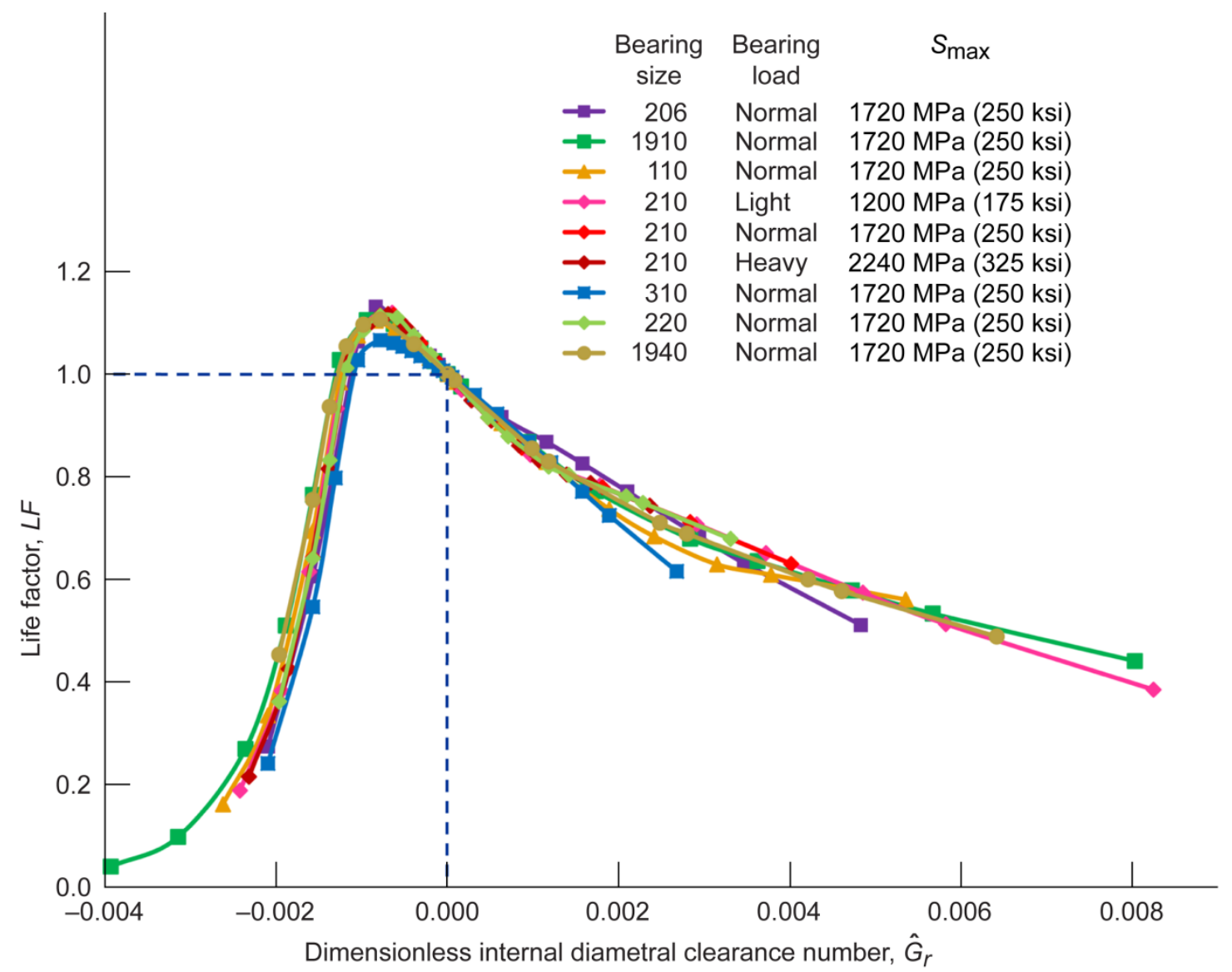

Figure 12.-Life factor versus dimensionless internal diametral clearance number for seven sizes of deepgroove ball bearings at three loads and three corresponding levels of maximum Hertz stress, $S_{\max }$. 
This simple relation is based on the static radial load capacity in terms of an acceptable level of deformation as defined by Palmgren (Ref. 3, p. 86): “... the allowable permanent deformation of rolling element and bearing ring [race] at a contact as 0.0001 times the diameter of the rolling element...." For radially loaded ball or cylindrical roller bearings, this corresponds to an $S_{\max }$ of either 4000 or $4200 \mathrm{MPa}(580$ or $609 \mathrm{ksi})$.

Oswald et al. (Ref. 20) used the Palmgren criteria (Ref. 3) to relate $S_{\max }$ to the applied radial load $P_{r}$ for radial load in either ball or roller bearings:

$$
S_{\max }=k_{2}\left[\frac{P_{r}}{C_{o r}}\right]^{(1 / i)}
$$

where the conversion constant $k_{2}=4000 \mathrm{MPa}$ (580 ksi) is the stress corresponding to a radial load equal to the static radial load capacity, $C_{o r}$ is the static radial load capacity of the bearing, which can be found in a bearing catalog, and $i=3$ for ball bearings and $i=2$ for roller bearings. Equation (39) implicitly assumes zero internal bearing clearance.

The value of $k_{2}=4000 \mathrm{MPa}(580 \mathrm{ksi})$ was implicitly included in the static load ratings in the 1978 revision of ANSI/ABMA standard 9 (Ref. 21). In the most recent (2000) revision (ANSI/ABMA-9 (Ref. 22)), this permissible stress has been increased by 5 percent to $4200 \mathrm{MPa}(609 \mathrm{ksi})$. The corresponding ISO standard (ISO 76 (Ref. 23)) also specifies the larger value, $4200 \mathrm{MPa}$. Herein $k_{2}=4000$ was used because it agrees better with the catalog values used (Ref. 19).

By substituting the value $1720 \mathrm{MPa}$ for $S_{\text {max }}^{\prime}$ and using Equation (39) for $S_{\max }$ and simplifying, the dimensionless internal diametral clearance number $\hat{G}_{r}$ can be found without solving for the actual stress in the bearing:

$$
\begin{aligned}
& \hat{G}_{r}=0.185 \frac{G_{r}}{d}\left(\frac{C_{o r}}{P_{r}}\right)^{2 / 3} \quad \text { for ball bearings } \\
& \hat{G}_{r}=0.185 \frac{G_{r}}{d}\left(\frac{C_{o r}}{P_{r}}\right) \quad \text { for roller bearings }
\end{aligned}
$$

where $G_{r}$ is the internal diametral bearing clearance and $d$ is the rolling-element diameter.

Figure 13 shows the same life factor data for deep-groove ball bearings as is shown in Figure 12 plotted on semi-log scales. Positive values of $\hat{G}_{r}$ are shown in the right half of the figure, and negative values of $\hat{G}_{r}$ are shown on the left half. Since negative values cannot be used with a log scale, absolute values of $\hat{G}_{r}$ were plotted and the axis was reversed and labeled with minus signs. Zero clearance, where by definition, $L F=1.0$, is not shown.

The data of Figure 13 were fitted piecewise to mathematical functions that allow $L F$ to be estimated for deep-groove ball bearings from the following equations. Curves of these functions are shown with the data in Figure 13.

$$
\begin{aligned}
& L F=600 \hat{G}_{r}+1.7 \quad-0.003 \leq \hat{G}_{r}<-0.00099 \\
& L F=\exp \left(-110 \hat{G}_{r}\right) \quad-0.00099 \leq \hat{G}_{r}<0.01
\end{aligned}
$$

The procedure for ball bearings described earlier in this section can also be applied to determine the effect of internal clearance on the life of cylindrical roller bearings. Figure 14 shows life factor $L F$ versus the dimensionless internal diametral clearance number $\hat{G}_{r}$ as calculated from Equation (40b) for seven different sizes of cylindrical roller bearings at normal

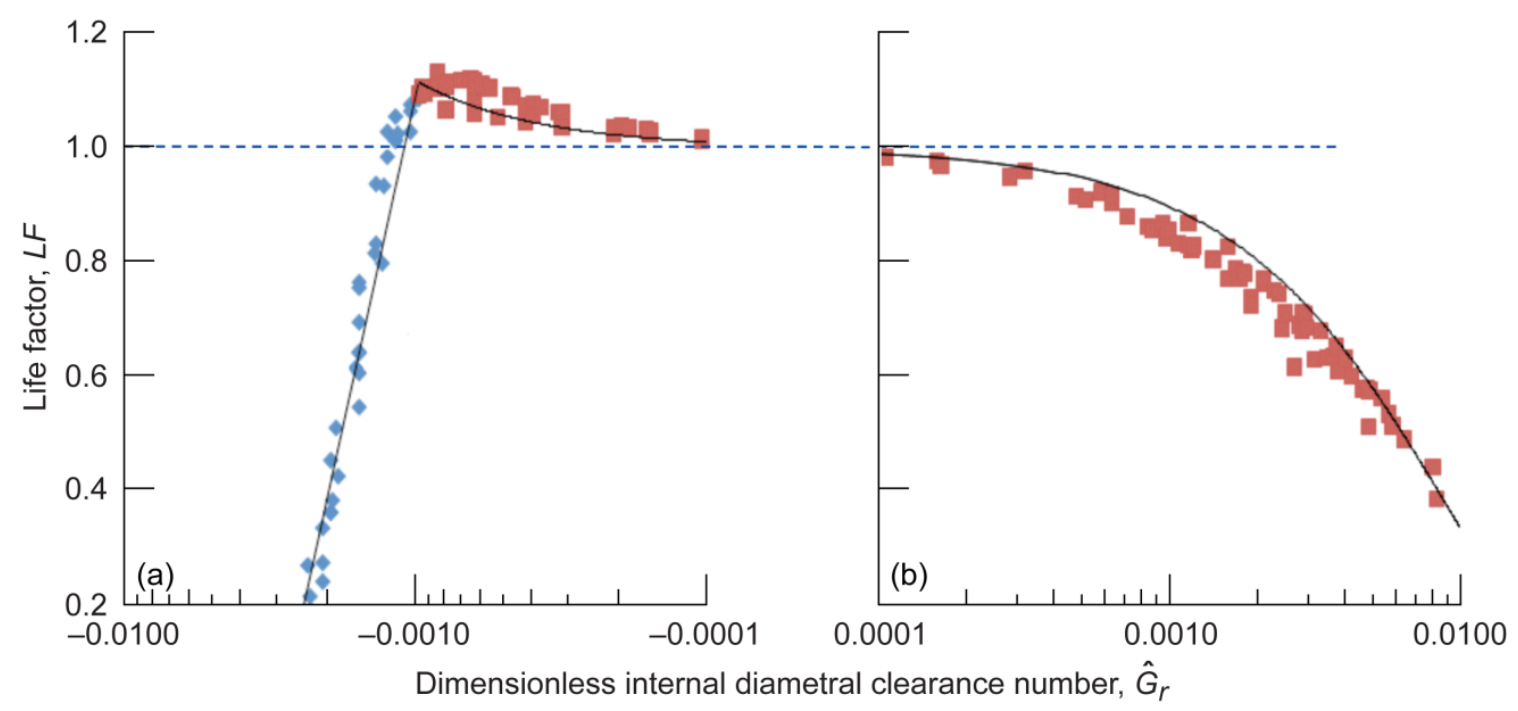

Figure 13.-Life factor for deep-groove ball bearings versus dimensionless internal diametral clearance number on a log scale. (a) Negative $\hat{G}_{r}$ (absolute value plotted with axis reversed). (b) Positive $\hat{G}_{r}$. The curves added to the figure represent curve fits applied to the data. 


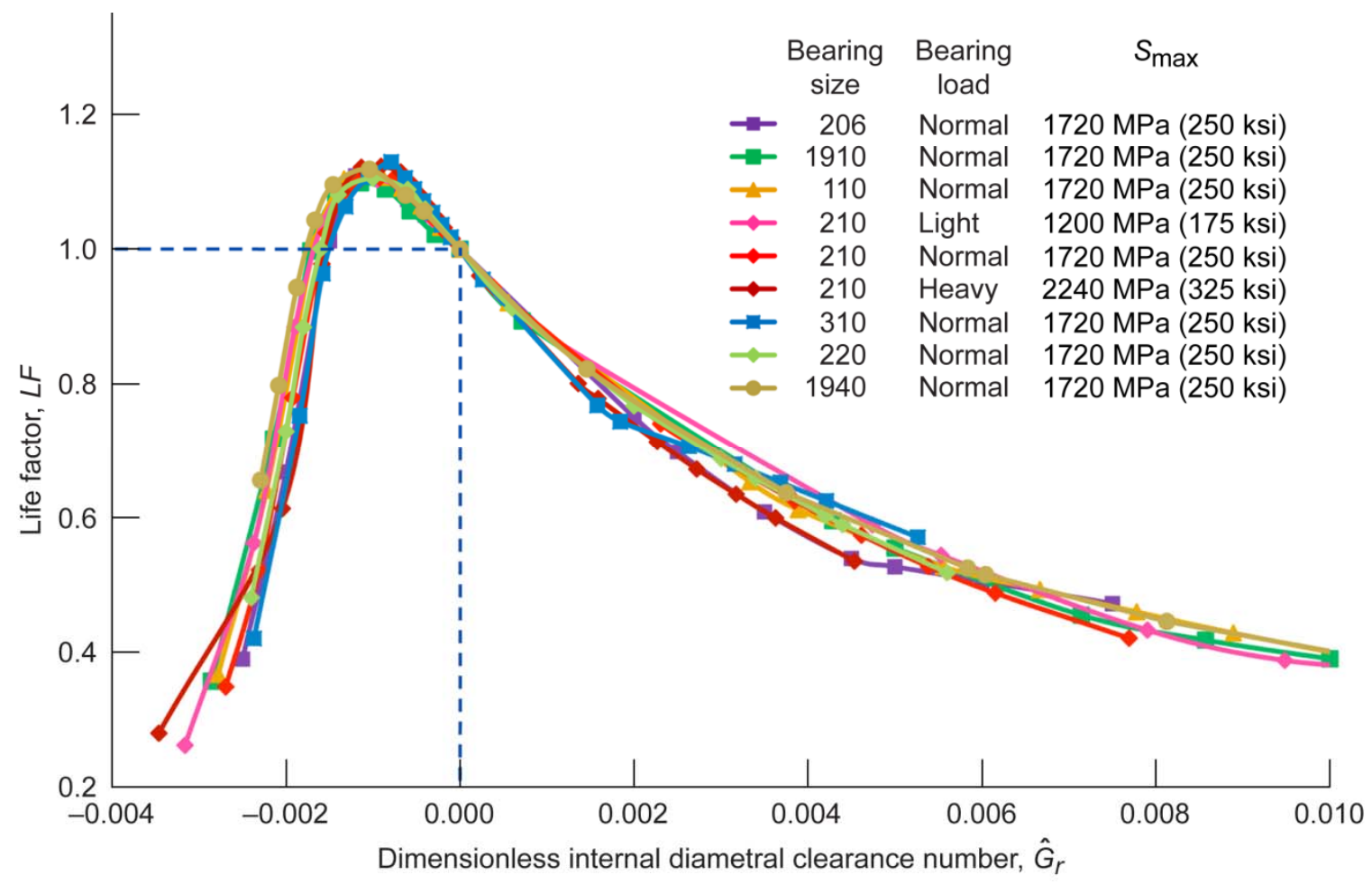

Figure 14.-Life factor versus dimensionless internal diametral clearance number for seven sizes of cylindrical roller bearings at three load levels and three corresponding levels of maximum Hertz stress, $S_{\text {max. }}$.

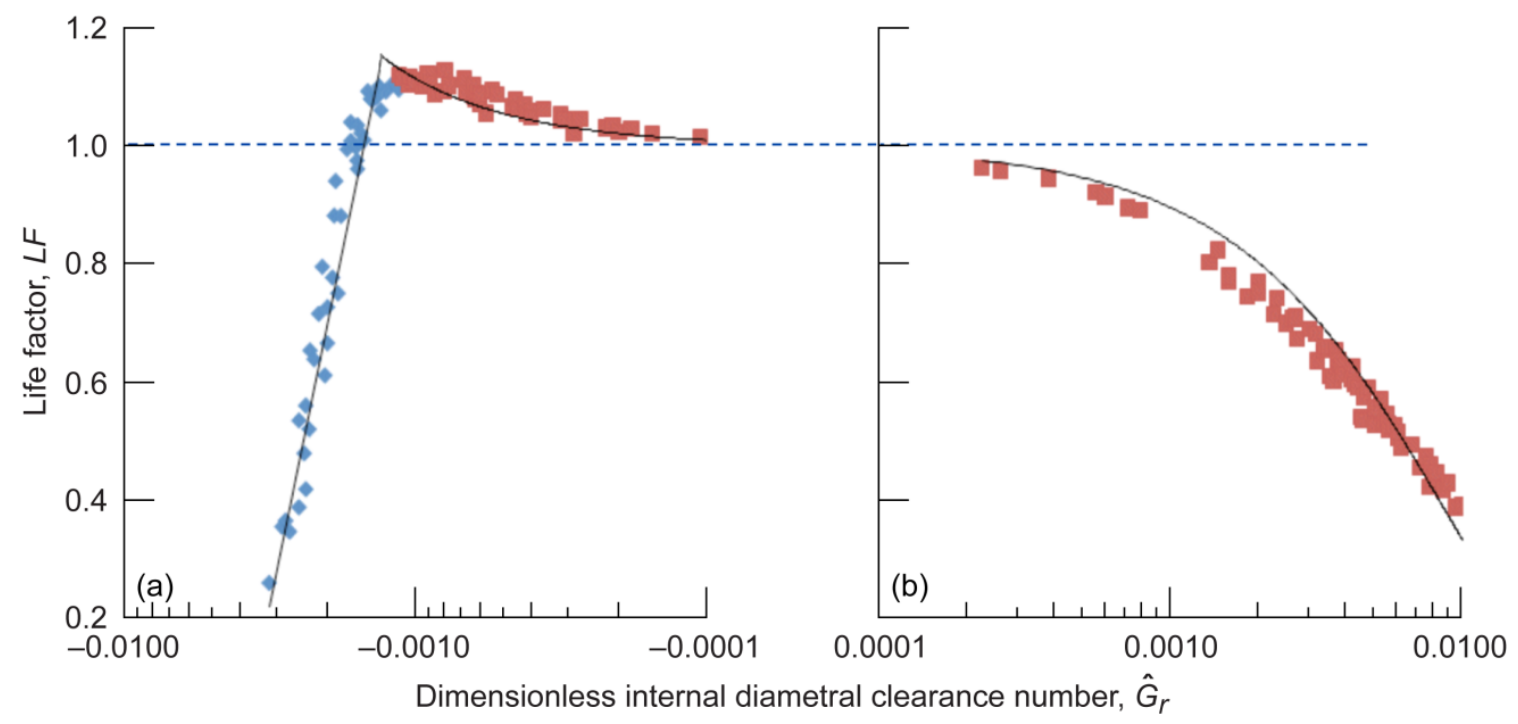

Figure 15.-Life factor for cylindrical roller bearings versus dimensionless internal diametral clearance number on a log scale. (a) Negative $\hat{G}_{r}$ (absolute value plotted with axis reversed). (b) Positive $\hat{G}_{r}$. The curves added to the figure represent curve fits applied to the data.

load. Normal load is defined as the load that produces a maximum Hertz stress $S_{\max }=1720 \mathrm{MPa}$ (250 ksi) for a bearing with zero internal clearance. In addition, there are curves for light and heavy loads for the 210 -size bearings. The maximum $L F=1.15$ for cylindrical roller bearings occurs with a small amount of negative clearance at $\hat{G}_{r}=-0.0013$. The clearance values for cylindrical roller bearings shown in Table IV are approximately twice the values specified for radial ball bearings in Table $\mathrm{V}$ at a given clearance group. Because of the larger clearances, roller bearings have smaller life factors than deep-groove ball bearings do, as can be seen by comparing Figures 12 and 14.

Figure 15 shows the same data as in Figure 14 plotted on semi-log scales. Positive values of $\hat{G}_{r}$ are shown in the right 
half of the figure, and negative values of $\hat{G}_{r}$ are shown on the left half using the same procedure as for Figure 13.

The data of Figure 15 were fitted piecewise to mathematical functions that allow the life factor $L F$ for cylindrical roller bearings to be estimated from the following equations. Curves of these functions are also shown in Figure 15.

$$
\begin{aligned}
& L F=500 \hat{G}_{r}+1.8 \quad-0.003 \leq \hat{G}_{r}<-0.0013 \\
& L F=\exp \left(-100 \hat{G}_{r}\right) \quad-0.0013 \leq \hat{G}_{r}<0.01
\end{aligned}
$$

\section{Stribeck Number and Maximum Rolling-Element Load as Affected by Internal Clearance}

In addition to the effect of clearance on life factor, we investigated the relation between the maximum rollingelement load and internal clearance. The Stribeck Number $S_{t}$, which relates the maximum element load on the bearing to the average rolling-element load, is defined in Equation (11).

Figure 16 shows $S_{t}$ versus $\hat{G}_{r}$ for seven different sizes of deep-groove ball bearings at normal load. The figure also includes $S_{t}$ for the 210-size bearings at light and heavy loads. Note that the value of $S_{t}$ found for zero internal clearance closely matches Stribeck's value of 4.37. The recommended value of 5.0 would be a reasonable estimate for bearings with small values of clearance except at light load. The minimum Stribeck Number for deep-groove ball bearings, $S_{t}=3.8$, occurs at $\hat{G}_{r}=-0.0012$. Note that the minimum $S_{t}$ occurs with a small negative clearance (interference).

Figure 17 shows the same ball bearing Stribeck Number data as in Figure 16 plotted on semi-log scales. Positive values of $\hat{G}_{r}$ are shown in the right half of the figure. Negative values of $\hat{G}_{r}$ are shown on the left half. Since negative values cannot be used in a log scale, absolute values were plotted and the axis was reversed and labeled with minus signs. Zero clearance, where $S_{t}$ approaches the asymptotic value of 4.37, is not shown.

The data of Figure 17 were fitted piecewise to mathematical functions that allow $S_{t}$ for deep-groove ball bearings to be estimated from the following equations:

$$
\begin{gathered}
S_{t}=2.668 \exp \left(-300 \hat{G}_{r}\right) \quad-0.003 \leq \hat{G}_{r}<-0.0012 \\
S_{t}=4.37 \exp \left(110 \hat{G}_{r}\right) \quad-0.0012<\hat{G}_{r}<0 \\
S_{t}=4.37 \exp \left(75 \hat{G}_{r}\right) \quad 0 \leq \hat{G}_{r}<0.01
\end{gathered}
$$

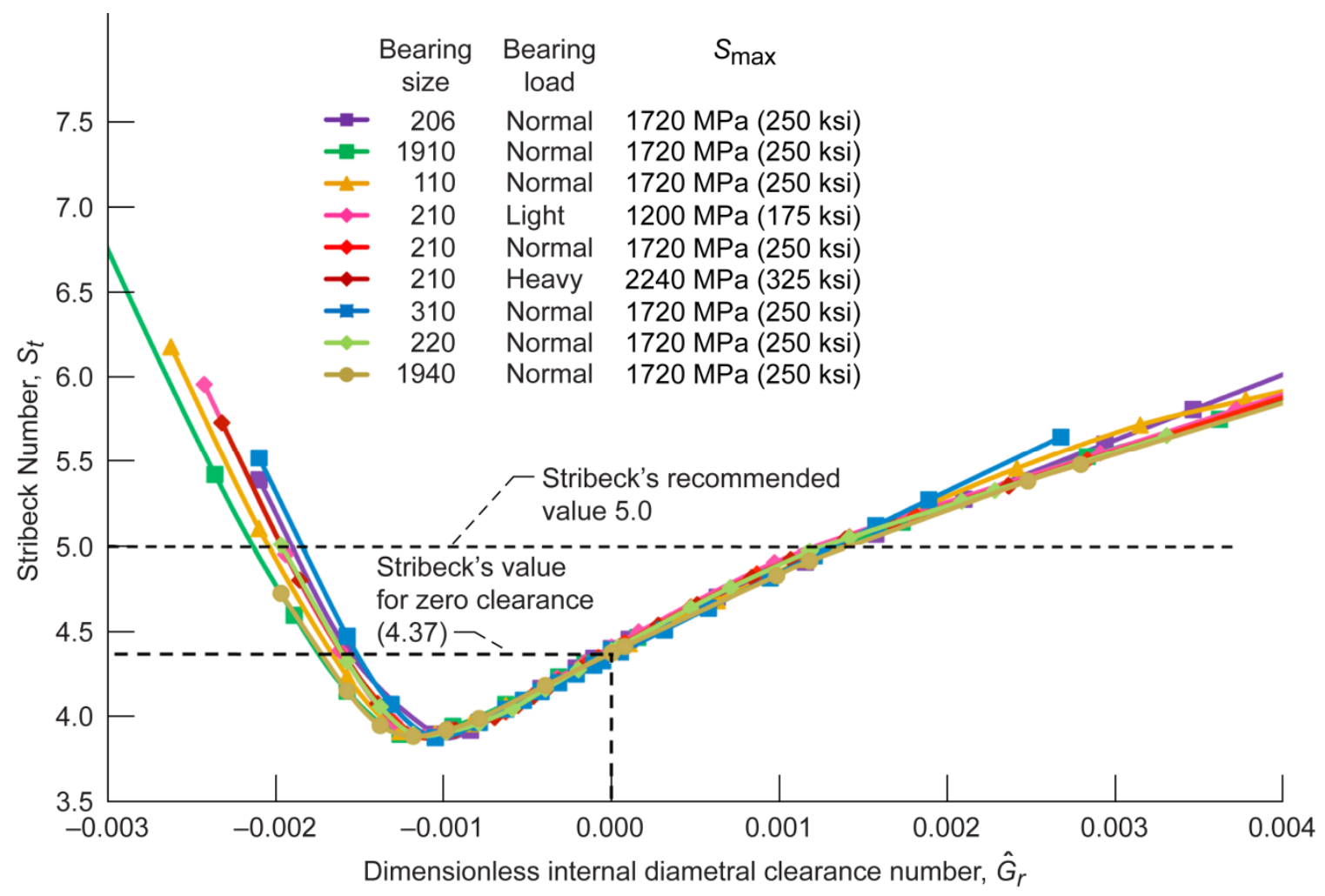

Figure 16.-Stribeck Number for deep-groove ball bearings versus dimensionless internal diametral clearance number. Curves show seven bearing sizes and include three load levels and three corresponding levels of maximum Hertz stress, $S_{\max }$. 


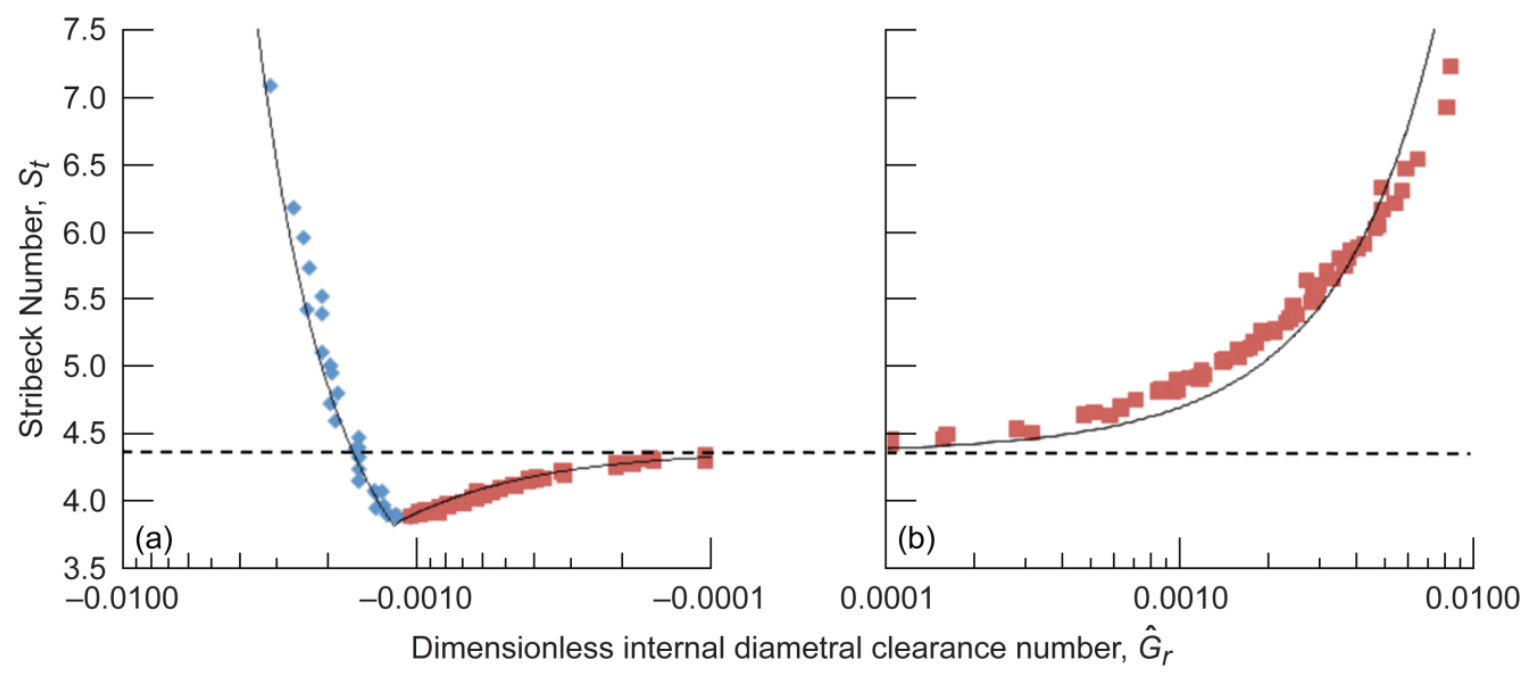

Figure 17.-Stribeck Number for deep-groove ball bearings versus dimensionless internal diametral clearance number on a log scale. (a) Negative $\hat{G}_{r}$ (absolute value plotted with axis reversed). (b) Positive $\hat{G}_{r}$. The curves added to the figure represent curve fits applied to the data.

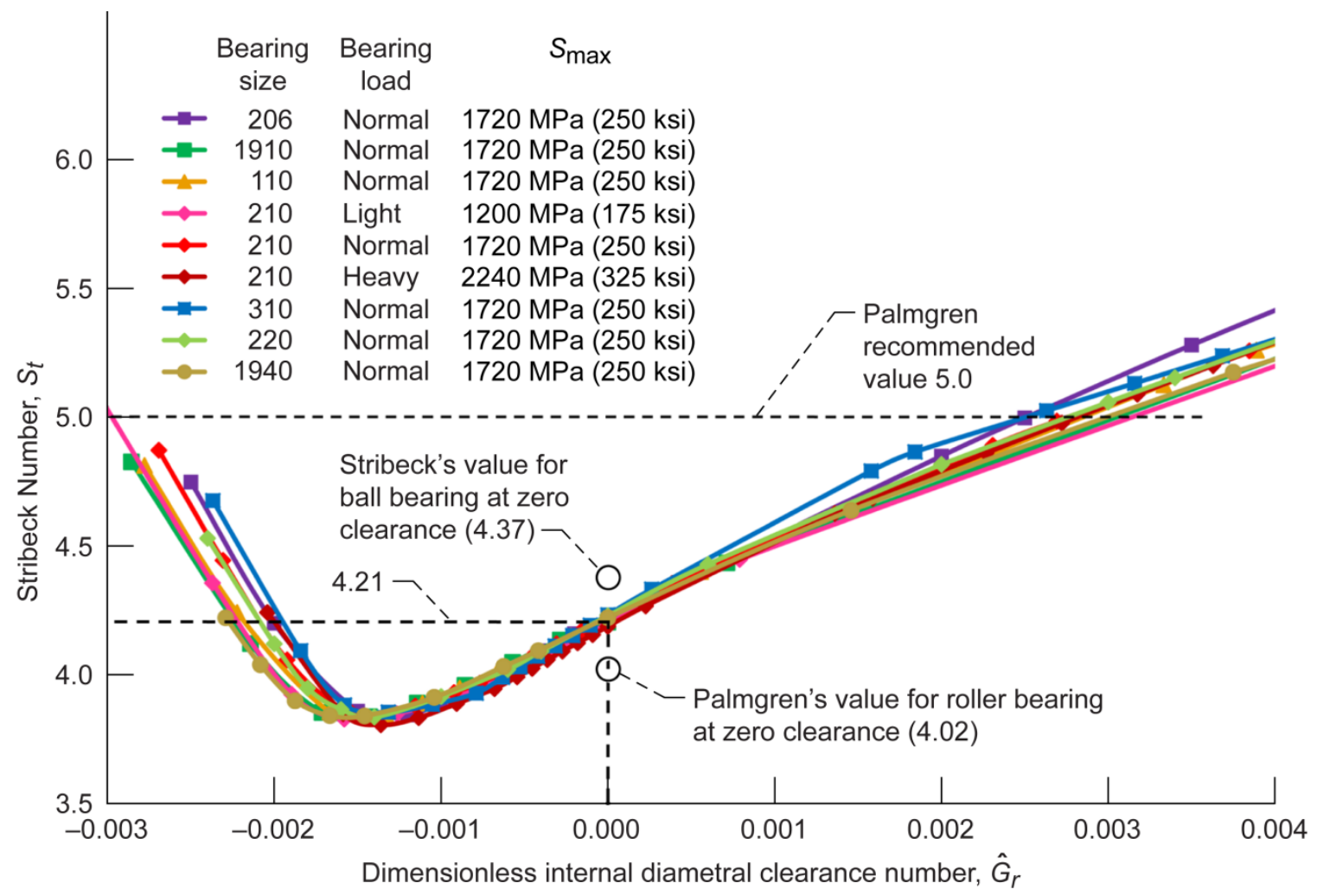

Figure 18.-Stribeck Number versus dimensionless internal diametral clearance number for seven sizes of cylindrical roller bearings at three load levels and three corresponding levels of maximum Hertz stress, $S_{\max }$.

In Figure 18, the Stribeck Number for cylindrical roller bearings was plotted in the same manner as it was for ball bearings earlier. At zero internal clearance, $S_{t}=4.21$, which is 3.7 percent less than for ball bearings and 3.2 percent greater than Palmgren's value of 4.08 for roller bearings. The minimum Stribeck Number for cylindrical roller bearings, $S_{t}=3.76$, occurs at $\hat{G}_{r}=-0.0016$ (negative clearance).

The Stribeck Number analysis just described was applied to cylindrical roller bearings with crowned rollers. Because we believed that Palmgren's analysis was for flat rollers (no 


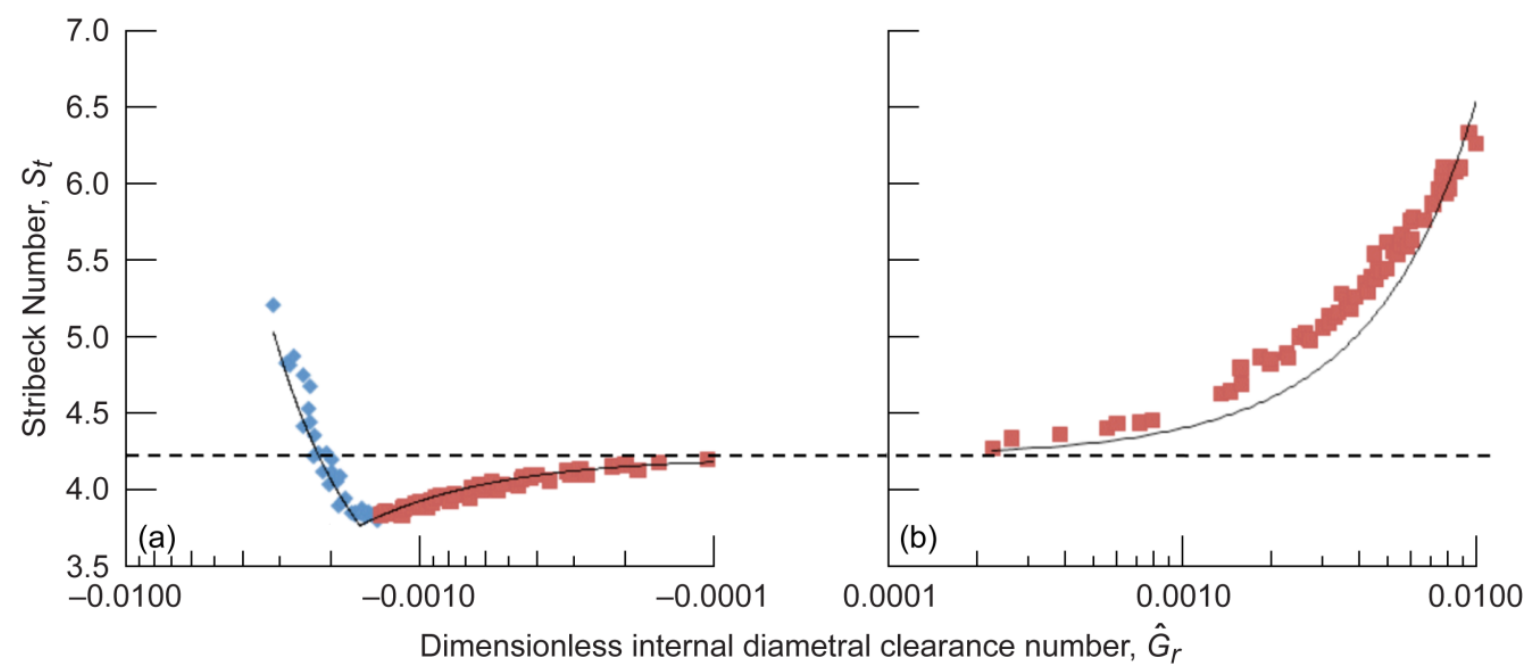

Figure 19.- - Stribeck Number for cylindrical roller bearings versus dimensionless internal diametral clearance number on a log scale. (a) Negative $\hat{G}_{r}$ (absolute value plotted with axis reversed). (b) Positive $\hat{G}_{r}$. The curves added to the figure represent curve fits applied to the data.

crown), we tried a single case for bearings with flat rollers. The result for zero clearance was $S_{t}=4.09$, which is very close to the 4.08 value obtained analytically earlier and by Palmgren (Ref. 3). This suggests that the Palmgren analysis was for bearings with flat rollers.

In Figure 19, the Stribeck Number data of Figure 18 were plotted on semi-log scales. Positive values of $\hat{G}_{r}$ are shown in the right half of the figure, and negative values of $\hat{G}_{r}$ are shown on the left half. The data of Figure 19 were fitted piecewise to mathematical functions that allow $S_{t}$ for cylindrical roller bearings to be estimated from Equation (44):

$$
\begin{gathered}
S_{t}=2.8 \exp \left(-185 \hat{G}_{r}\right) \quad-0.003 \leq \hat{G}_{r}<-0.0016 \\
S_{t}=4.21 \exp \left(70 \hat{G}_{r}\right) \quad-0.0016<\hat{G}_{r}<0 \\
S_{t}=4.21 \exp \left(44 \hat{G}_{r}\right) \quad 0 \leq \hat{G}_{r}<0.016
\end{gathered}
$$

Examples 3 and 4 of Appendix $\mathrm{F}$ illustrate the use of the curve-fit functions for calculating the Stribeck Number and maximum rolling-element load as presented in this section.

The Stribeck Number computed in the examples in the appendixes is significantly greater than the 5.0 value that Stribeck and Palmgren recommended, even though the clearance value was specified as the mid-range of "normal" clearance defined in the standards. Harris and Kotzalas (Ref. 11) warn that estimating the maximum rolling-element load with Equation (10) using the approximate constant 5.0 is inadequate for light loads or where the bearing rings are not rigid.

In addition, we calculated the Stribeck Number for Examples 3 and 4 of Appendix $\mathrm{F}$ except at a very light load, such that $S_{\max }=600 \mathrm{MPa}(87.5 \mathrm{ksi})$. For this case, $S_{t}$ is 7.5 and
7.8 for a deep-groove ball bearing and a cylindrical roller bearing, respectively, with mid-range "normal" clearance.

This result of the Stribeck Number becoming large for light loads can be anticipated if one considers the physical situation. As the applied radial load becomes very small, the elastic deflection at the contacts vanishes and all of the load is carried by a single rolling element. For this case, $P_{\max } \approx P_{r}$ and the Stribeck Number as defined by Equation (11) approaches $z$, the number of rolling elements.

\section{Summary of Results}

The effect of internal diametral clearance on the fatigue life and rolling-element load distribution was investigated for deep-groove ball bearings and cylindrical roller bearings. The load at the most heavily loaded rolling element was described in terms of the Stribeck Number $S_{t}$ defined as the maximum element load divided by the average element load. The Stribeck Number can be used to find the load distribution among the rolling elements in a bearing.

A procedure was developed for calculating the rollingelement loads for positive or negative clearance from the load-distribution integral as introduced by Sjövall (Ref. 12). Empirical equations also were developed for calculating the maximum rolling-element load and life factors in low-speed cylindrical roller bearings and deep-groove ball bearings. The following results were obtained:

1. The effect of a given value of operating internal clearance on the load distribution and fatigue life of rollingelement bearings varies with the rolling-element size and not the bore size or pitch diameter. 
2. The "dimensionless internal diametral clearance number" $\hat{G}_{r}$ can be calculated from the bearing internal clearance, rolling-element diameter, static load capacity, and applied load. The parameter $\hat{G}_{r}$ can be used to estimate the Stribeck Number $S_{t}$ and the bearing life factor $L F$.

3. The concept of a Stribeck Number, $S_{t}=P_{\max } /\left(P_{r} / z\right)$, was derived to relate bearing internal clearance to the maximum rolling-element load for radially loaded ball and roller bearings, where $P_{\max }$ is the maximum element load, $P_{r}$ is the applied radial load, and $z$ is the number of rolling-elements.

4. The analysis confirmed that $S_{t}=4.37$ for ball bearings at zero internal clearance and $S_{t}=4.08$ for roller bearings at zero clearance. The roller bearing number agrees with Palmgren's value of 4.08. For roller bearings with a specified aerospace crown on the rollers, $S_{t}=4.21$. For bearings with clearance, $S_{t}$ approaches $z$ as the applied radial load approaches zero. 


\section{Appendix A.-Symbols}

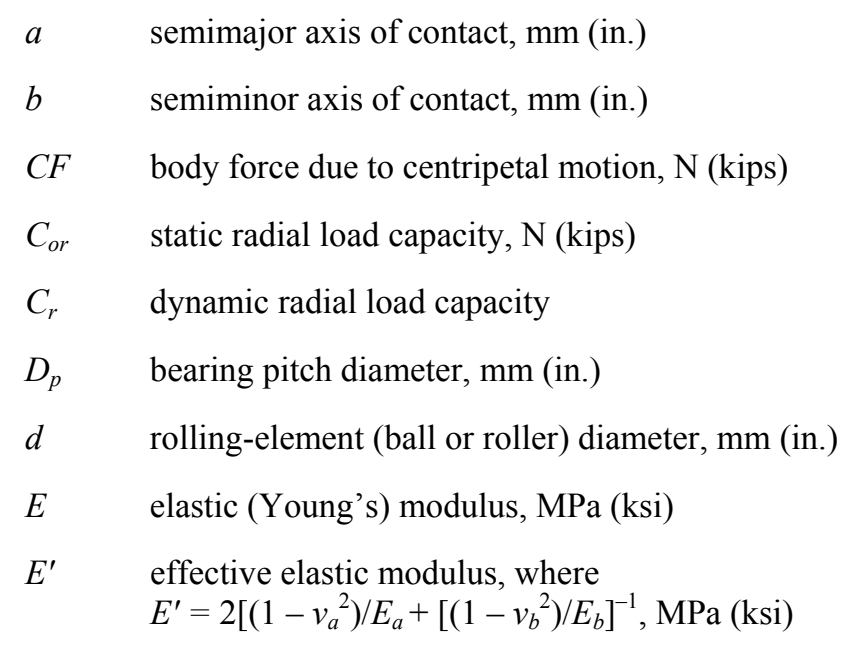

$\varepsilon(\alpha) \quad$ elliptic integral of the second kind

$F_{x} \quad$ applied radial load in the $\mathrm{x}$ direction, $\mathrm{N}(\mathrm{lb})$

$F_{y} \quad$ applied radial load in the y direction, N (lb)

$\mathfrak{I}(\alpha) \quad$ elliptic integral of the first kind

$f$ race conformity, ratio of race groove radius to bearing ball diameter

$G_{r} \quad$ internal diametral clearance, $\mathrm{mm}$ (in.)

$G_{r}^{\prime} \quad$ nondimensional internal diametral clearance, $G_{r} / d$

$\hat{G}_{r} \quad$ dimensionless internal diametral clearance number

$g \quad$ radial clearance, $\mathrm{mm}$ (in.)

INT integer function

$i \quad$ stress-load exponent in Equation (39)

$J_{r} \quad$ load-distribution integral

$j \quad$ rolling-element number (index)

$K \quad$ stiffness, $\mathrm{N} / \mathrm{m}$ (lb/in.)

$k(\alpha) \quad$ ellipticity parameter, $a / b$

$k_{1} \quad$ conversion constant for Equation (19)

$k_{2} \quad$ conversion constant for Equation (39)

$L \quad$ life of rolling-element bearing, hours or millions of inner-ring revolutions

$L_{0} \quad$ life at zero clearance of rolling-element bearing, hours or millions of inner-ring revolutions
$L_{10} \quad 10$-percent fatigue life for the bearing

$L F \quad$ life factor for internal clearance

$l_{e} \quad$ roller effective length, m (in.)

$m \quad$ mass, $\mathrm{g}\left(\mathrm{lb}_{\mathrm{m}}\right)$

$n$ number of pairs of loaded elements in Equations (1), (8a), and (14a)

$P \quad$ load, N (kips)

$P_{j} \quad$ load on rolling-element $j, \mathrm{~N}$ (kips)

$P_{\max } \quad$ maximum rolling-element radial load, N (kips)

$P_{r} \quad$ applied radial load on bearing, $\mathrm{N}$ (kips)

$Q \quad$ factor in Equation (9) relating applied load to maximum element load

$R \quad$ effective radius of curvature, where $R=(\Sigma(1 / r))^{-1}, \mathrm{~m}$ (in.)

$S_{\max } \quad$ maximum Hertz stress on inner ring, MPa (ksi)

$S_{\max }^{\prime} \quad$ reference value of maximum Hertz stress, $1720 \mathrm{MPa}$ (250 ksi)

$S_{t} \quad$ Stribeck Number defined in Equation (11)

$z \quad$ number of rolling elements

$\alpha \quad$ load/deformation exponent-For roller bearings, $\alpha=1.11$; for ball bearings, $\alpha=1.5$.

$\beta \quad$ angle between the rolling elements, radians (deg)

$\Delta \quad$ displacement of inner race in Equation (15)

$\delta \quad$ deflection of rolling elements and races under load, $\mathrm{mm}$ (in.)

$\delta_{\max } \quad$ maximum elastic race deformation (under maximumloaded rolling element), $\mathrm{mm}$ (in.)

$\delta_{T} \quad$ total race deflection including elastic deformation and clearance takeup, $\mathrm{mm}$ (in.)

$\varepsilon \quad$ load-zone parameter, where $\varepsilon=1 / 2-G_{r} /\left(4 \delta_{T}\right)$

$\varepsilon^{\prime} \quad$ residual force in Equations (22a) and (22b) (error term for iterative calculation), $\mathrm{N}\left(\mathrm{lb}_{\mathrm{f}}\right)$

$v \quad$ elastic constant

$\psi \quad$ position angle from maximum-loaded rolling element, radians (deg) 
$\psi_{1}$

$\omega \quad$ rotating speed, $\mathrm{rad} / \mathrm{s}$

\section{Subscripts}

$a, b \quad$ refers to body $a$ or $b$

$i \quad$ inner race of bearing $j \quad$ rolling-element number (index)

$n \quad$ normal direction

$o \quad$ outer race of bearing

$x \quad$ tangential direction (i.e., in rolling direction)

$y \quad$ transverse direction 


\section{Appendix B.-Derivation of Equation (20a) for Roller-Race Stiffness in a Roller Bearing}

Anderson (Ref. 1), based on Palmgren (Ref. 3), shows that the approach (deflection) between the axis of a finite-length cylinder and an infinite plane can be expressed as

$$
\delta=0.39 \cdot\left(\theta_{a}+\theta_{b}\right)^{0.9} \cdot P^{0.9} / l_{e}^{0.8}
$$

where $P$ is the load, $l_{e}$ is the effective cylinder (roller) length, and $\theta$ is defined in terms of the elastic constants $E$ and $v$ as $\theta=4\left(1-v^{2}\right) / E$, which need not be the same for bodies $a$ and $b$. These elastic constants can be expressed in terms of the effective modulus $E^{\prime}$ as

$$
\left(\theta_{a}+\theta_{b}\right)=4\left[\frac{\left(1-v_{a}^{2}\right)}{E_{a}}+\frac{\left(1-v_{b}^{2}\right)}{E_{b}}\right]=\frac{8}{E^{\prime}}
$$

Substituting the effective modulus from Equation (B2) into Equation (B1), gives the deflections, $\delta_{i}$ and $\delta_{o}$, at the inner and outer races:

$$
\delta_{i} \approx \delta_{o}=2.537 \cdot \frac{P^{0.9}}{\left(E^{\prime}\right)^{0.9} l_{e}^{0.8}}
$$

Solving for the force $P$ gives

$$
P=\frac{E^{\prime} l_{e}^{8 / 9} \cdot \delta^{10 / 9}}{2.537^{10 / 9}}=0.3555 E^{\prime} l_{e}^{8 / 9} \delta^{10 / 9}
$$

Defining the stiffness $K=P / \delta^{\alpha}$ (recall that for line contact, $\alpha=10 / 9 \approx 1.11$ ), and with the outer and inner race stiffnesses nearly equal, gives

$$
K_{i j} \approx K_{o j}=0.3555 \cdot E^{\prime} l_{e}^{1.11}
$$

If the roller and race are the same material, the effective modulus simplifies to $E^{\prime}=E /\left(1-v^{2}\right)$. 



\section{Appendix C.-Derivation of Equations (20b) and (20c) for Ball-Race Stiffness in a Radially Loaded Ball Bearing}

Hamrock and Anderson (Ref. 17) give the maximum ballrace deflection as

$$
\delta_{\max }=\mathfrak{I}(\alpha)\left[\left(\frac{9}{2 \cdot \mathcal{E}(\alpha) R}\right)\left(\frac{P_{\max }}{\pi k(\alpha) E^{\prime}}\right)^{2}\right]^{1 / 3}
$$

In Equation (C1), the deflection should be calculated separately for the inner and outer races from terms defined in Equations (29) to (33). The stiffnesses in Equations (18a) and (18b) are defined as $K=P / \delta^{\alpha}$ (where, for point contact, $\alpha=3 / 2$ ). Thus,

$$
\begin{gathered}
\delta_{\max }^{3 / 2}=\sqrt{\frac{9 \cdot \mathfrak{I}(\alpha)^{3}}{2 \cdot \mathcal{E}(\alpha) R}} \cdot \frac{P_{\max }}{\pi k(\alpha) E^{\prime}} \\
K=\frac{P}{\delta^{3 / 2}}=\pi k(\alpha) E^{\prime} \sqrt{\frac{2 \cdot \mathcal{E}(\alpha) R}{9 \cdot \mathfrak{I}^{3}(\alpha)}}
\end{gathered}
$$

This article presents a simplified approximate method from Hamrock and Anderson (Ref. 17) to calculate the ellipticity parameters in Equations (C1) to (C3). Computer solutions (Ref. 18) typically employ an iterative procedure using Hertz contact theory as presented in Jones (Refs. 13 and 14). 



\section{Appendix D.-Example Calculations to Determine the Stribeck Number and Maximum Rolling-Element Load From the Approximate Method}

This appendix provides two examples that illustrate the use of the load-distribution integral approximate method to determine maximum rolling-element loads for deep-groove ball bearings and cylindrical roller bearings that have either positive or negative clearance.

\section{Example 1-Stribeck Number and Maximum Ball Load in a Deep-Groove Ball Bearing}

Consider a 210-size deep-groove ball bearing, with midband group $\mathrm{N}$ clearance and carrying a light radial load $P_{r}=627 \mathrm{~N}(0.141 \mathrm{kips})$. This load was chosen such that at zero clearance it produces an inner-race maximum Hertz stress of $1200 \mathrm{MPa}(175 \mathrm{ksi})$. The properties (Table II) include the following: $z=10$ balls of diameter $d=12.7 \mathrm{~mm}(0.5 \mathrm{in}$.), the ratio of race groove radius to bearing ball diameter $f=0.52$, and the pitch diameter $D_{p}=70.000 \mathrm{~mm}$ (2.7559 in.).

From ANSI/ABMA-20 (Ref. 4) (Table IV), group N internal diametral clearance for this ball bearing ranges from 0.006 to $0.023 \mathrm{~mm}$ ( 0.00025 to 0.00090 in.). Thus, $G_{r}=0.0145 \mathrm{~mm}$ (0.00057 in.).

For steel rollers and races, $E=205900 \mathrm{MPa}$ (29 $900 \mathrm{ksi})$, $v=0.3$, and the effective modulus $E^{\prime}=226240 \mathrm{MPa}$ (32 $800 \mathrm{ksi})$.

For a ball bearing, several geometry parameters must be calculated:

1. Compute the effective radii of curvature from Equations (29a) and (29b):

$$
\begin{aligned}
& R_{i}=\left[\frac{2 \cdot 70}{12.7(70-12.7)}+\frac{2 \cdot 0.52-1}{0.52 \cdot 12.7}\right]^{-1}=5.039 \mathrm{~mm}(0.1984 \text { in. }) \\
& R_{o}=\left[\frac{2 \cdot 70}{12.7(70+12.7)}+\frac{2 \cdot 0.52-1}{0.52 \cdot 12.7}\right]^{-1}=7.176 \mathrm{~mm}(0.2825 \mathrm{in} .)
\end{aligned}
$$

2. Compute the radius ratios from Equations (30a) and (30b):

$$
\alpha_{i}=\frac{2 \cdot 0.52 \cdot 70}{(70-12.7)(2 \cdot 0.52-1)}=31.763
$$

and

$$
\alpha_{o}=\frac{2 \cdot 0.52 \cdot 70}{(70+12.7)(2 \cdot 0.52-1)}=22.007
$$

3. Compute the ellipticity parameters from Equation (31):

$k_{i}=(31.763)^{2 / \pi}=9.040 \quad$ and $\quad k_{o}=(22.007)^{2 / \pi}=7.157$
4. Compute the first and second elliptic integrals from Equations (32) and (33):

$$
\begin{gathered}
\mathfrak{I}_{i}=\pi / 2+(\pi / 2-1) \ln (31.763)=3.545 \\
\mathfrak{I}_{o}=\pi / 2+(\pi / 2-1) \ln (22.007)=3.335 \\
\boldsymbol{\varepsilon}_{i}=1+(\pi / 2-1) / 31.763=1.018 \\
\boldsymbol{\varepsilon}_{o}=1+(\pi / 2-1) / 22.007=1.026
\end{gathered}
$$

5. Compute the stiffnesses of the inner and outer races from Equations (20b) and (20c):

$$
\begin{aligned}
& K_{i}=\pi \cdot 9.04 \cdot 226240 \sqrt{\frac{2 \cdot 1.018 \cdot 5.039}{9 \cdot(3.545)^{3}}} \\
&= 1.028 \times 10^{6} \mathrm{~N} / \mathrm{mm}^{1.5}\left(29579 \mathrm{kips} / \mathrm{in} .{ }^{1.5}\right) \\
& K_{o}=\pi \cdot 7.157 \cdot 226240 \sqrt{\frac{2 \cdot 1.026 \cdot 7.176}{9 \cdot(3.335)^{3}}} \\
&=1.068 \times 10^{6} \mathrm{~N} / \mathrm{mm}^{1.5}\left(30737 \mathrm{kips} / \mathrm{in}^{1.5}\right)
\end{aligned}
$$

6. Compute the combined normal stiffness $K_{n}$ from Equation (27):

$$
\begin{aligned}
K_{n}=\left[(1 / 1.028)^{2 / 3}\right. & \left.+(1 / 1.068)^{2 / 3}\right]^{-3 / 2} \times 10^{6} \\
& =3.704 \times 10^{5} \mathrm{~N} / \mathrm{mm}^{1.5}\left(10659 \mathrm{kips} / \mathrm{in}^{1.5}\right)
\end{aligned}
$$

7. For computing the maximum ball loads, use Stribeck's (Ref. 2) suggested value for the Stribeck Number, $S_{t}=5$, as a starting guess.

8. Compute the initial estimate of the load-distribution integral:

$$
J_{r}(\varepsilon)=1 / S_{t}=1 / 5=0.200
$$

9. Compute the initial estimate of the total displacement $\delta_{T}$ from Equation (35):

$\delta_{T}=\frac{0.0145}{2}+\left[\frac{627}{10 \cdot 3.704 \times 10^{6} \cdot 0.20}\right]^{2 / 3}$

$$
=0.01620 \mathrm{~mm}(0.000661 \mathrm{in} .)
$$


10. Compute the load-zone parameter:

$$
\varepsilon=1 / 2-G_{r} /\left(4 \delta_{T}\right)=0.5-(0.0145) /(4 \cdot 0.0162)=0.2762
$$

11. Recompute the load-distribution integral $J_{r}(\varepsilon)$ from Equation (26a) since $0.1 \leq \varepsilon<0.5$ :

$$
J_{r}=0.3076(0.2762)^{0.4175}=0.1805
$$

12. Compute $S_{t}=1 / J_{r}=5.539$. This value for $S_{t}$ differs significantly from the starting guess of 5.0, thus further iteration is needed.

Steps 7 to 12 were repeated with $S_{t}=5.539$, which yielded a new value of 5.494. On the third iteration, $S_{t}=5.494$ yielded a new value of 5.499. Further iterations alternated between 5.498 and 5.499. We chose $S_{t}=5.499$. This value is 2.5 percent greater than the value found from the analysis code for this 210-size deep-groove ball bearing.

\section{Example 2-Stribeck Number and Maximum Ball Load in a Cylindrical Roller Bearing}

Consider a 210-size cylindrical roller bearing, analogous to Example 1 with mid-band group $\mathrm{N}$ clearance and carrying a light radial load, $P_{r}=6940 \mathrm{~N}$ (1.56 kips). This load was chosen such that, at zero clearance, it produces a inner-race maximum Hertz stress of $1200 \mathrm{MPa}(175 \mathrm{ksi})$. Properties (Table III) include the following: $z=14$ rollers of diameter $d=13 \mathrm{~mm}(0.512 \mathrm{in}$.) and length $l=13 \mathrm{~mm}(0.5118 \mathrm{in}$.). The pitch diameter $D_{p}=70.65 \mathrm{~mm}$ (2.7815 in.).

From ANSI/ABMA-20 (Ref. 4) (Table V), group N internal diametral clearance for this roller bearing ranges from 0.030 to $0.060 \mathrm{~mm}\left(0.0012\right.$ to 0.0024 in.). Thus, $G_{r}=0.045 \mathrm{~mm}$ (0.0018 in.).

The elastic constants are the same as in Example 1, thus $E^{\prime}=226240 \mathrm{MPa}$ (32 $\left.800 \mathrm{ksi}\right)$. We assumed crowned rollers; hence we should adjust the roller length. Typically the effective roller length is 85 to 90 percent of $l$. For this lightly loaded example, we assumed 85 percent; hence $l_{e}=11.05 \mathrm{~mm}$ (0.4350 in.).

1. Compute the combined normal stiffness from Equation (28):

$$
\begin{aligned}
K_{n}=0.1647 \cdot 226240 \cdot(11.05)^{8 / 9} & \\
= & 3.153 \times 10^{5} \mathrm{~N} / \mathrm{mm}^{1.11}\left(2579 \mathrm{kips} / \mathrm{in} .{ }^{1.11}\right)
\end{aligned}
$$

2. Begin iteration assuming Palmgren's (Ref. 3) suggested value for the Stribeck Number, $S_{t}=5$

3. Compute the initial estimate of the load-distribution integral:

$$
J_{r}(\varepsilon)=1 / S_{t}=0.20
$$

4. Compute the initial estimate of the total deflection $\delta_{T}$ from Equation (35):

$$
\begin{aligned}
\delta_{T}=\frac{0.045}{2}+\left[\frac{6940}{14 \cdot 3.153 \cdot 10^{5} \cdot 0.20}\right]^{1 / 1.11} & \\
= & 0.03521 \mathrm{~mm}(0.0001385 \mathrm{in} .)
\end{aligned}
$$

5. Compute the load-zone parameter:

$$
\varepsilon=1 / 2-G_{r} /\left(4 \delta_{T}\right)=0.5-(0.045) /(4 \cdot 0.03521)=0.1805
$$

6. Recompute the load-distribution integral $J_{r}(\varepsilon)$ from Equation (25a):

$$
J_{r}=0.3268(0.1805)^{0.4023}=0.1643
$$

7. Compute $S_{t}=1 / J_{r}=6.086$. This value differs significantly from the starting guess of 5.0, thus further iteration is needed.

We repeated steps 2 to 7 choosing $S_{t}=6.086$, which yielded a new value of 5.831. After three further iterations, $S_{t}$ converged to 5.876 . This value differs by less than 0.01 percent of the value found from the analysis code for this 210 -size roller bearing.

For large values of negative clearance (interference), this method of iterating using the load-distribution integral may not give stable convergence with an "automatic" procedure that uses the prior estimate for the next iteration. If the clearance value in Example 2 is changed to $G_{r}=-0.02$, and the initial estimate of $S_{t}=5.0$, the procedure produces a very large calculated value $S_{t}=8.5$. One must override this estimate, choosing more moderate iteration steps to converge to the final value of $S_{t}=5.897$ with residual $<0.001$. 


\section{Appendix E.-Alternative Method to Determine the Stribeck Number and Maximum Element Load}

The following procedure can be used to calculate the Stribeck Number and maximum element load in deep-groove ball bearings and cylindrical roller bearings that have zero or positive internal clearance. It does not give good results for negative clearance.

1. Make a starting guess for the Stribeck Number, using our knowledge of the value for zero clearance, where $S_{t}=4.37$ for ball bearings or 4.08 for cylindrical roller bearings. Also consider the typical value for a small clearance at moderate load, $S_{t} \approx 5$.

2. Compute the maximum ball load from the initial guess for $S_{t}$ from Equation (10).

3. Compute the elastic deflections at both races, $\delta_{i}$ and $\delta_{o}$, from Equation (B3) for roller bearings or from Equation (C1) for ball bearings.

4. Compute the total deflection:

$$
\delta_{T}=\delta_{i}+\delta_{o}+G_{r} / 2
$$

5. Compute the load-zone parameter:

$$
\varepsilon=1 / 2-G_{r} /\left(4 \delta_{T}\right)
$$

6. Compute the maximum element load $P_{\max }$ from $\delta_{T}$ from Equations (E1) and (E2) (based on Hamrock and Anderson (Ref. 17)). These equations are valid for zero or positive clearance, $G_{r} \geq 0$, where $\varepsilon \leq 0.5$.
For a cylindrical roller bearing,

$$
P_{\max }=\frac{4 \pi \varepsilon\left(\frac{P_{r}}{z}\right)}{\psi_{l}-(1-2 \varepsilon) \sin \psi_{l}}
$$

where the limiting contact angle $\psi_{1}$ is given by Equation (24). For a deep-groove ball bearing,

$$
P_{\max }=\frac{\pi \cdot(2 \varepsilon)^{3 / 2}\left(\frac{P_{r}}{z}\right)}{2.491\left[\sqrt{1+\left(\frac{2 \varepsilon}{1.23}\right)^{2}}-1\right]}
$$

7. Compute the Stribeck Number $S_{t}$ from Equation (11).

If the Stribeck Number from step 7 differs significantly from the initial guess, repeat steps 1 to 7 using a refined estimate for $S_{t}$. 



\section{Appendix F.-Determining the Life Factor and Stribeck Number for Internal Clearance for Ball and Roller Bearings From Bearing Catalog Data}

Two examples are presented to show the simple method for determining bearing life factor and Stribeck Number from the bearing clearance $G_{r}$, the rolling-element diameter $d$, the static radial load capacity $C_{o r}$, the load on the bearing $P_{r}$, and the reference value of maximum Hertz stress, $S_{\max }^{\prime}=1700 \mathrm{MPa}$ (250 ksi).

\section{Example 3-Life Factor and Stribeck Number for Internal Clearance in a Deep-Groove Ball Bearing}

Consider a 210 -size deep-groove ball bearing with middleof-the-tolerance-band, group $\mathrm{N}$ clearance that is carrying a light radial load $P_{r}=627 \mathrm{~N}(141 \mathrm{lb})$. This is the same bearing, with the same clearance and at the same load, as in Example 1 in Appendix C. From Table II, there are $z=10$ balls of diameter $d=12.7 \mathrm{~mm}(0.5 \mathrm{in}$.). From the bearing catalog, the static radial load capacity $C_{o r}=23162 \mathrm{~N}(5207 \mathrm{lb})$.

From ANSI/ABMA-20 (Ref. 4) (Table IV), the group N clearance for this ball bearing ranges from 0.006 to $0.023 \mathrm{~mm}$ $(0.0025$ to 0.009 in.). With mid-band clearance, $G_{r}=0.0145 \mathrm{~mm}(0.00057$ in. $)$.

1. Compute the dimensionless internal diametral clearance number from Equation (40a):

$$
\hat{G}_{r}=0.185 \frac{0.0145}{12.7}\left(\frac{23162}{627}\right)^{2 / 3}=0.002343
$$

2. Compute the life factor from Equation (41b), which is valid for $-0.000986 \leq \hat{G}_{r}>0.01$ :

$$
L F=\exp (-110 \cdot 0.002343)=0.77
$$

3. Compute the Stribeck Number from Equation (43c), which is valid for $0 \leq \hat{G}_{r}>0.01$ :

$$
S_{t}=4.37 \cdot \exp (75 \cdot 0.002343)=5.21
$$

The life factor is about 4 percent larger than the analysis code result, and the Stribeck Number is 3 percent less than the analysis code value.

\section{Example 4-Life Factor and Stribeck Number for Internal Clearance in a Cylindrical Roller Bearing}

Consider a 210-size cylindrical roller bearing with middleof-the-tolerance-band, group $\mathrm{N}$ clearance that is carrying a light radial load of $6940 \mathrm{~N}(1560 \mathrm{lb})$. This is the same bearing, with the same clearance and the same load as in Example 2 in Appendix C. From Table III, there are $z=14$ rollers of diameter $d=13 \mathrm{~mm}(0.512 \mathrm{in}$.). The static radial load capacity $C_{\text {or }}=77226 \mathrm{~N}(17361 \mathrm{lb})$.

From ANSI/ABMA-20 (Ref. 4) (Table V), group N clearance for this bearing ranges from 0.030 to $0.060 \mathrm{~mm}(0.0012$ to 0.0024 in.). With mid-band clearance, $G_{r}=0.045 \mathrm{~mm}$ (0.00177 in.).

1. Compute the dimensionless internal diametral clearance number from Equation (40b):

$$
\hat{G}_{r}=0.185 \frac{0.045}{13}\left(\frac{77226}{6940}\right)=0.007126
$$

2. Compute the life factor from Equation (42b), which is valid for $-0.00132 \leq \hat{G}_{r}>0.01$ :

$$
L F=\exp (-100 \cdot 0.007126)=0.49
$$

3. Compute the Stribeck Number from Equation (44c), which is valid for $0 \leq \hat{G}_{r}>0.016$ :

$$
S_{t}=4.21 \cdot \exp (44 \cdot 0.007126)=5.76
$$

The life factor is about 5 percent larger than the analysis code result, and the Stribeck Number is 2 percent less than the analysis code value. 



\section{References}

1. Anderson, W.J.: Rolling-Element Bearings. Advanced Bearing Technology, E.E. Bisson and W.J. Anderson, eds., NASA/SP-38, 1964, pp. 164-168.

2. Stribeck, R.: Ball Bearings for Various Loads. Reports From the Central Laboratory for Scientific Technical Investigation, Translation by K.W. Van Treuren et al., ASME Trans., vol. 29, 1907, pp. 420-463.

3. Palmgren, A.: Ball and Roller Bearing Engineering. Third ed., SKF Industries, Philadelphia, PA, 1959.

4. American Bearing Manufacturer Association (ABMA) Radial Bearings of Ball, Cylindrical Roller and Spherical Roller Types-Metric Design. ANSI/ABMA 20-1996, American Bearing Manufacturers Association, Washington, DC, 2001.

5. International Organization for Standardization (ISO): Rolling Bearings - Internal Clearance-Part 1: Radial Internal Clearance for Radial Bearings. ISO 5753-1, International Organization for Standardization, Geneva, Switzerland, 2009.

6. Lundberg, G.; and Palmgren, A.: Dynamic Capacity of Rolling Bearings. Acta Polytechnica Mech. Eng. Ser., vol. 1, no. 3 (also Ingeniörs Vetenskaps Akademiens Handlingar, 1947, p. 196), Stockholm, Sweden, 1947.

7. Lundberg, G.; and Palmgren, A.: Dynamic Capacity of Roller Bearings, No. 210, The Royal Swedish Academy of Engineering Sciences, Stockholm, Sweden, 1952.

8. Sadeghi, F., et al.: A Review of Rolling Contact Fatigue. J. Tribol., vol. 131, no. 4, 2009.

9. Elmidany, T., et al.: Optimal Interference in Radial Cylindrical Roller Bearings. J. Engineering Applied Science-Cairo, vol. 54, no. 2, 2007, pp. 189-204.

10. Harris, T.A.: How to Compute the Effects of Preloaded Bearings. Prod. Eng., vol. 19, 1965, pp. 84-93.

11. Harris, T.A.; and Kotzalas, M.N.: Rolling Bearing Analysis. Vol. 1, CRC Press, Boca Raton, FL, 2007.

12. Sjövall, Harald: Belastningsfördelningen inom Kul-Och Rull-Lager Vid Givna Yttre Radial-Och Axialbelastningar
(The Load Distribution Within Ball and Roller Bearings Under Given External Radial and Axial Load), Teknisk Tidskrift (Technical Magazine), Mek., h. 9 (in Swedish), 1933.

13. Jones, A.B.: New Departure-Analysis of Stresses and Deflections. Vols. I and II. New Departure Div., General Motors Corp., Bristol, CT, 1946.

14. Jones, A.B.: The Mathematical Theory of RollingElement Bearings, Mechanical Design and Systems Handbook. Sect. 13, H.A. Rothbart, ed., McGraw-Hill, New York, NY, 1964.

15. Houpert, L.: A Uniform Analytical Approach for Ball and Roller Bearing. J. Tribol., vol. 119, 1997, pp. 851-857.

16. Houpert, L.: An Engineering Approach to Hertzian Contact Elasticity-Part I. J. Tribol., vol. 123, 2001, pp. 582-588.

17. Hamrock, B.J.; and Anderson, W.J.: Rolling-Element Bearings. NASA RP-1105/REV1, 1983.

18. Poplawski, J.V., et al.: Advanced Analysis Package for High Speed Multibearing Shaft Systems: COBRA-AHS. Final report, NASA Contract NAS3-00018, 2002.

19. Timken Aerospace Design Guide for Precision Metric Ball and Cylindrical Roller Bearings. http:/www.timken.com/en-us/products/bearings/productlist/ aerospace/Documents/aerospace product design guide.pdf Accessed August 31, 2011.

20. Oswald, F.B.; Zaretsky, E.V.; and Poplawski, J.V.: Interference Fit Life Factors for Ball Bearings. Tribol. Trans., vol. 54, no. 1, 2011, pp. 1-20.

21. ANSI/AFBMA Std. 9-1978: Load Ratings and Fatigue Life for Ball Bearings. Anti-Friction Bearing Manufacturers Association, Washington, DC, 1978.

22. ANSI/ABMA-9:1990 (R2000): Load Ratings and Fatigue Life for Ball Bearings. American Bearing Manufacturers Association, Washington, DC, 2000.

23. ISO 76:2006: Rolling Bearings-Static Load Ratings. International Organization for Standardization, Geneva, Switzerland, 2006. 


\begin{tabular}{|c|c|c|}
\hline \multicolumn{2}{|c|}{ REPORT DOCUMENTATION PAGE } & $\begin{array}{l}\text { Form Approved } \\
\text { OMB No. 0704-0188 }\end{array}$ \\
\hline \multicolumn{3}{|c|}{ 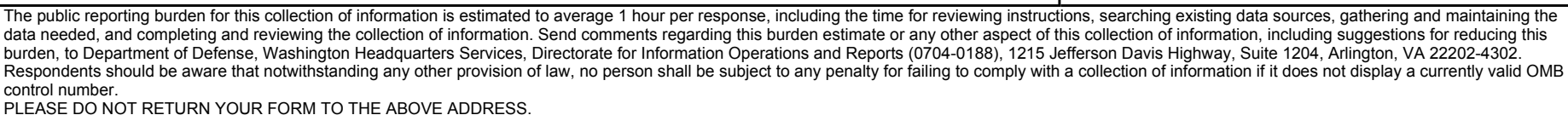 } \\
\hline $\begin{array}{l}\text { 1. REPORT DATE (DD-MM-YYYY) } \\
01-04-2012\end{array}$ & $\begin{array}{l}\text { 2. REPORT TYPE } \\
\text { Technical Memorandum }\end{array}$ & 3. DATES COVERED (From - To) \\
\hline \multirow{3}{*}{\multicolumn{2}{|c|}{$\begin{array}{l}\text { 4. TITLE AND SUBTITLE } \\
\text { Effect of Internal Clearance on Load Distribution and Life of Radially Loaded Ball and Roller } \\
\text { Bearings }\end{array}$}} & 5a. CONTRACT NUMBER \\
\hline & & 5b. GRANT NUMBER \\
\hline & & 5c. PROGRAM ELEMENT NUMBER \\
\hline \multirow{3}{*}{\multicolumn{2}{|c|}{$\begin{array}{l}\text { 6. AUTHOR(S) } \\
\text { Oswald, Fred, B.; Zaretsky, Erwin, V.; Poplawski, Joseph, V. }\end{array}$}} & 5d. PROJECT NUMBER \\
\hline & & 5e. TASK NUMBER \\
\hline & & $\begin{array}{l}\text { 5f. WORK UNIT NUMBER } \\
\text { WBS 877868.02.07.03.01.01.01 }\end{array}$ \\
\hline \multicolumn{2}{|c|}{$\begin{array}{l}\text { 7. PERFORMING ORGANIZATION NAME(S) AND ADDRESS(ES) } \\
\text { National Aeronautics and Space Administration } \\
\text { John H. Glenn Research Center at Lewis Field } \\
\text { Cleveland, Ohio 44135-3191 }\end{array}$} & $\begin{array}{l}\text { 8. PERFORMING ORGANIZATION } \\
\text { REPORT NUMBER } \\
\text { E-17247-1 }\end{array}$ \\
\hline \multirow{2}{*}{\multicolumn{2}{|c|}{$\begin{array}{l}\text { 9. SPONSORING/MONITORING AGENCY NAME(S) AND ADDRESS(ES) } \\
\text { National Aeronautics and Space Administration } \\
\text { Washington, DC 20546-0001 }\end{array}$}} & $\begin{array}{l}\text { 10. SPONSORING/MONITOR'S } \\
\text { ACRONYM(S) } \\
\text { NASA }\end{array}$ \\
\hline & & $\begin{array}{l}\text { 11. SPONSORING/MONITORING } \\
\text { REPORT NUMBER } \\
\text { NASA/TM-2012-217115 }\end{array}$ \\
\hline \multicolumn{3}{|c|}{$\begin{array}{l}\text { 12. DISTRIBUTION/AVAILABILITY STATEMENT } \\
\text { Unclassified-Unlimited } \\
\text { Subject Category: } 37 \\
\text { Available electronically at http://www.sti.nasa.gov } \\
\text { This publication is available from the NASA Center for AeroSpace Information, 443-757-5802 }\end{array}$} \\
\hline
\end{tabular}

\section{ABSTRACT}

The effect of internal clearance on radially loaded deep-groove ball and cylindrical roller bearing load distribution and fatigue life was determined for four clearance groups defined in the bearing standards. The analysis was extended to negative clearance (interference) conditions to produce a curve of life factor versus internal clearance. Rolling-element loads can be optimized and bearing life maximized for a small negative operating clearance. Life declines gradually with positive clearance and rapidly with increasing negative clearance. Relationships were found between bearing life and internal clearance as a function of ball or roller diameter, adjusted for load. Results are presented as life factors for radially loaded bearings independent of bearing size or applied load. In addition, a modified Stribeck Equation is presented that relates the maximum rolling-element load to internal bearing clearance.

\section{SUBJECT TERMS}

Bearings; Roller bearings; Ball bearings; Fatigue life; Contact loads; Clearance

\begin{tabular}{|c|c|c|c|c|c|}
\hline \multicolumn{3}{|c|}{ 16. SECURITY CLASSIFICATION OF: } & \multirow{2}{*}{$\begin{array}{l}\text { 17. LIMITATION OF } \\
\text { ABSTRACT } \\
\text { UU }\end{array}$} & \multirow{2}{*}{$\begin{array}{l}\text { 18. NUMBER } \\
\text { OF } \\
\text { PAGES } \\
39\end{array}$} & \multirow{2}{*}{$\begin{array}{l}\text { 19a. NAME OF RESPONSIBLE PERSON } \\
\text { STI Help Desk (email:help@sti.nasa.gov) } \\
\text { 19b. TELEPHONE NUMBER (include area code) } \\
\text { 443-757-5802 }\end{array}$} \\
\hline $\begin{array}{l}\text { a. REPORT } \\
\text { U }\end{array}$ & $\begin{array}{l}\text { b. ABSTRACT } \\
\text { U }\end{array}$ & $\begin{array}{l}\text { c. THIS } \\
\text { PAGE } \\
\text { U }\end{array}$ & & & \\
\hline
\end{tabular}


